\title{
Seismic source and structure estimation in the western Mediterranean using a sparse broadband network
}

\author{
Hong Kie Thio, ${ }^{1}$ Xi Song, ${ }^{2}$ Chandan K. Saikia, ${ }^{1}$ Donald V. Helmberger, ${ }^{2}$ \\ and Bradley B. Woods ${ }^{1}$
}

\begin{abstract}
We present a study of regional earthquakes in the western Mediterranean geared toward the development of methodologies and path calibrations for source characterization using regional broadband stations. The results of this study are useful for the monitoring and discrimination of seismic events under a comprehensive test ban treaty, as well as the routine analysis of seismicity and seismic hazard using a sparse array of stations. The area consists of several contrasting geological provinces with distinct seismic properties, which complicates the modeling of seismic wave propagation. We started by analyzing surface wave group velocities throughout the region and developed a preliminary model for each of the major geological provinces. We found variations of crustal thickness ranging from $45 \mathrm{~km}$ under the Atlas and Betic mountains and $37 \mathrm{~km}$ under the Saharan shield, to $20 \mathrm{~km}$ for the oceanic crust of the western Mediterranean Sea, which is consistent with earlier works. Throughout most of the region, the upper mantle velocities are low which is typical for tectonically active regions. The most complex areas in terms of wave propagation are the Betic Cordillera in southern Spain and its north African counterparts, the Rif and Tell Atlas mountains, as well as the Alboran Sea, between Spain and Morocco. The complexity of the wave propagation in these regions is probably due to the sharp velocity contrasts between the oceanic and continental regions as well as the the existence of deep sedimentary basins that have a very strong influence on the surface wave dispersion. We used this preliminary regionalized velocity model to correct the surface wave source spectra for propagation effects which we then inverted for source mechanism. We found that this method, which is in use in many parts of the world, works very well, provided that data from several stations are available. In order to study the events in the region using very few broadband stations or even a single station, we developed a hybrid inversion method which combines $P_{n l}$ waveforms synthesized with the traditional body wave methods, with surface waves that are computed using normal modes. This procedure facilitates the inclusion of laterally varying structure in the Green's functions for the surface waves and allows us to determine source mechanisms for many of the larger earthquakes $(M>4)$ throughout the region with just one station. We compared our results with those available from other methods and found that they agree quite well. The epicentral depths that we have obtained from regional waveforms are consistent with observed teleseismic depth phases, as far as they are available. We also show that the particular upper mantle structure under the region causes the various $P_{n}$ and $S_{n}$ phases to be impulsive, which makes them a useful tool for depth determination as well. Thus we conclude that with proper calibration of the seismic structure in the region and high-quality broadband data, it is now possible to characterize and study events in this region, both with respect to mechanism and depth, with a limited distribution of regional broadband stations.
\end{abstract}

\section{Introduction}

The present deployment of broadband digital stations in the Mediterranean region can be very valuable for tectonic studies, studies of seismic hazard, and nuclear test ban treaty verification. Because of the strong lateral heterogeneity in the region, it is necessary to develop sophisticated methods and proper calibrations in order to use these stations effectively. In this paper we present the results of our efforts in this direction. We illustrate the level of lateral heterogeneity and its influence on different parts of the seismic

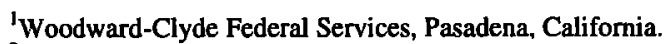

${ }^{2}$ Seismological Laboratory, California Institute of Technology, Pasadena.

Copyright 1999 by the American Geophysical Union.

Paper number 98JB01498

0148-0227/99/98JB-01498\$09.00.
}

wave train, followed by a presentation of focal mechanisms and depth determinations for several events that can be used for calibration purposes. Finally, we present a hybrid source-inversion method using $P_{n l}$ and surface waves that is suited for regions with few broadband stations and strongly laterally varying structure.

\subsection{Regional Tectonics}

The western Mediterranean region, including southern Spain and northern Africa, consists of several contrasting geologic provinces. The tectonically most active areas are found along the coast of North Africa, from the Gulf of Sirte to the east to the Strait of Gibraltar to the west, along the southern coast of Spain, and along the eastern and southern margins of the Tyrrhenian Basin (Plate 1). The major tectonic provinces in the region are the Betic, Rif and Tell Atlas mountains, the Alboran Sea, the Atlas mountains, and the Tuareg and West-African shields.

Subcrustal earthquakes occur in two zones, at the Calabrian arc under the Tyrrhenian Sea, where a well-defined subduction zone 


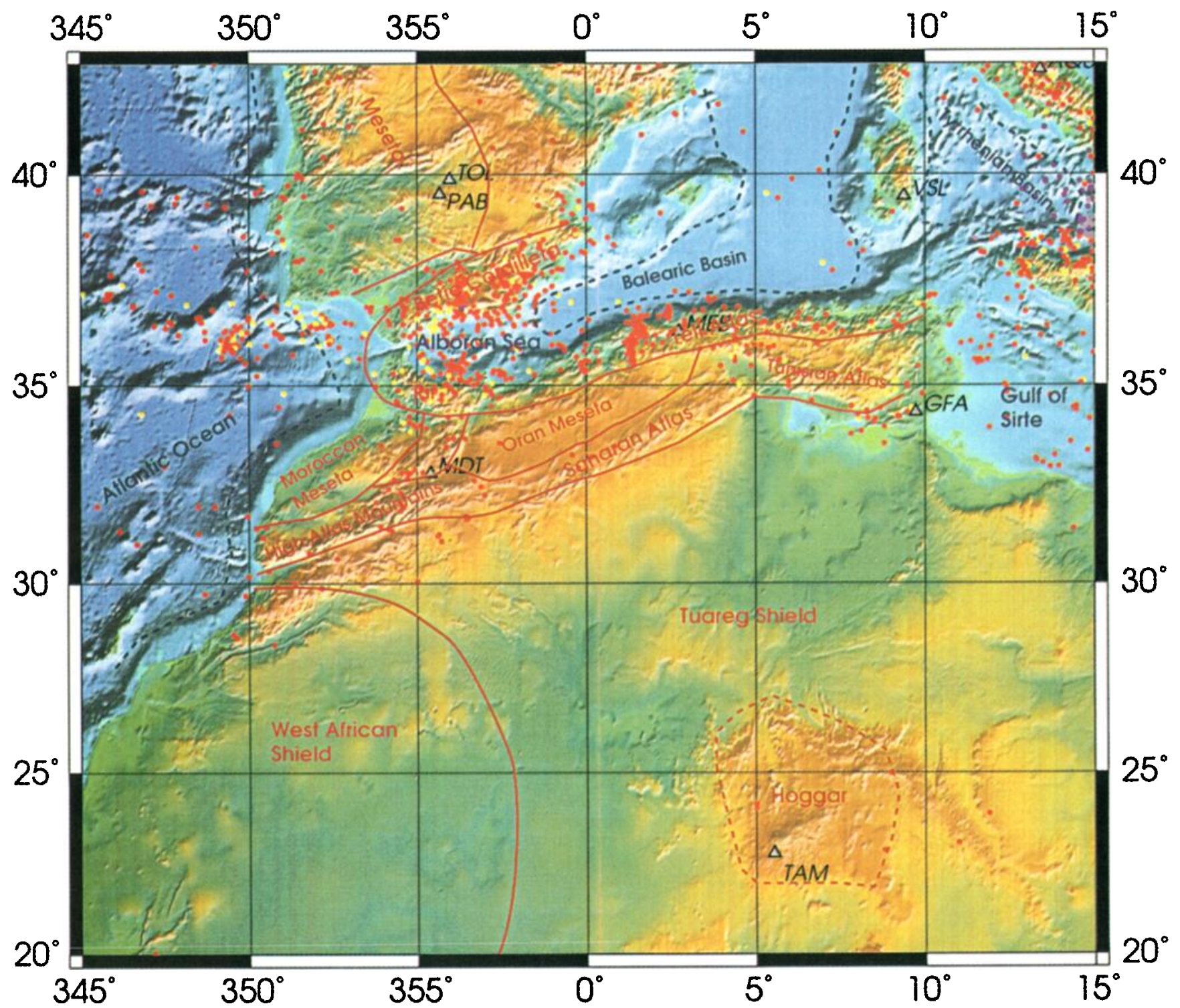

Plate 1. Topographic map of the study area showing the main tectonic units referred to in the text, seismic stations (triangles, with station names italicized) and seismicity from the ISC catalog (1900-1995): red dots for shallow events $(z<33 \mathrm{~km})$, yellow dots for intermediate events $(33<z<100 \mathrm{~km})$, light purple dots for deep events $(100<z<250$ $\mathrm{km})$, and dark purple for very deep events $(z>250 \mathrm{~km})$. Oceanic basins are delimited with dashed blue lines. The red solid lines are boundaries between the main tectonic subdivisions, and the igneous Hoggar plateau is bounded by red dashed lines.

exists and around the Alboran Sea, where earthquakes occur in a diffuse pattern down to a depth of $150 \mathrm{~km}$, except for a very small area near Granada (Plate 2), where earthquakes occur at a depth greater than $600 \mathrm{~km}$. However, in this paper we confine our attention to crustal events.

The Betic Cordillera of southern Spain on one end and the Rif Mountains of Morocco and the Tell Atlas of northern Algeria on the other end are mirror images of each other, and these mountain ranges form the opposing limbs of a very tight arcuate structure, the arc of Gibraltar. The mountains are part of the Alpine orogeny.

The western termination of the Mediterranean Sea between the Betic Cordillera and Rif Mountains, called the Alboran Sea, is regarded as a tectonic entity separate from the rest of the Mediterranean and probably more related to the Betic/Rif regions. The Alboran Sea is a very deep sedimentary basin containing Pliocene and Quarternary sediments with thicknesses up to $3 \mathrm{~km}$. Originat- ing as continental crust, the Alboran Sea underwent extension during the Miocene. The on-land Cheliff basin, located in and along the Tell Atlas in northern Algeria, is similar in content to the Alboran basin and reaches sediment thicknesses of up to $5 \mathrm{~km}$.

Away from the Betic/Rif/Tell massifs we find the high plateaux, the Meseta in Spain, on which station TOL (Toledo) and its successor PAB (San Pablo) are located, and the Moroccan and Oran Meseta's in Morocco and Algeria. These and the main Atlas ranges are of prealpine age but have been active during the Alpine orogeny as well. There is considerable seismic activity along the High Atlas mountains.

The Precambrian shields south of the Atlas mountains can be divided into two platforms, the West-African shield, which has not seen any tectonic activity since the late Precambrian, and the Touareg shield, which is part of the trans Saharan mobile belt, a Precambrian shield which has undergone major tectonic activity in 


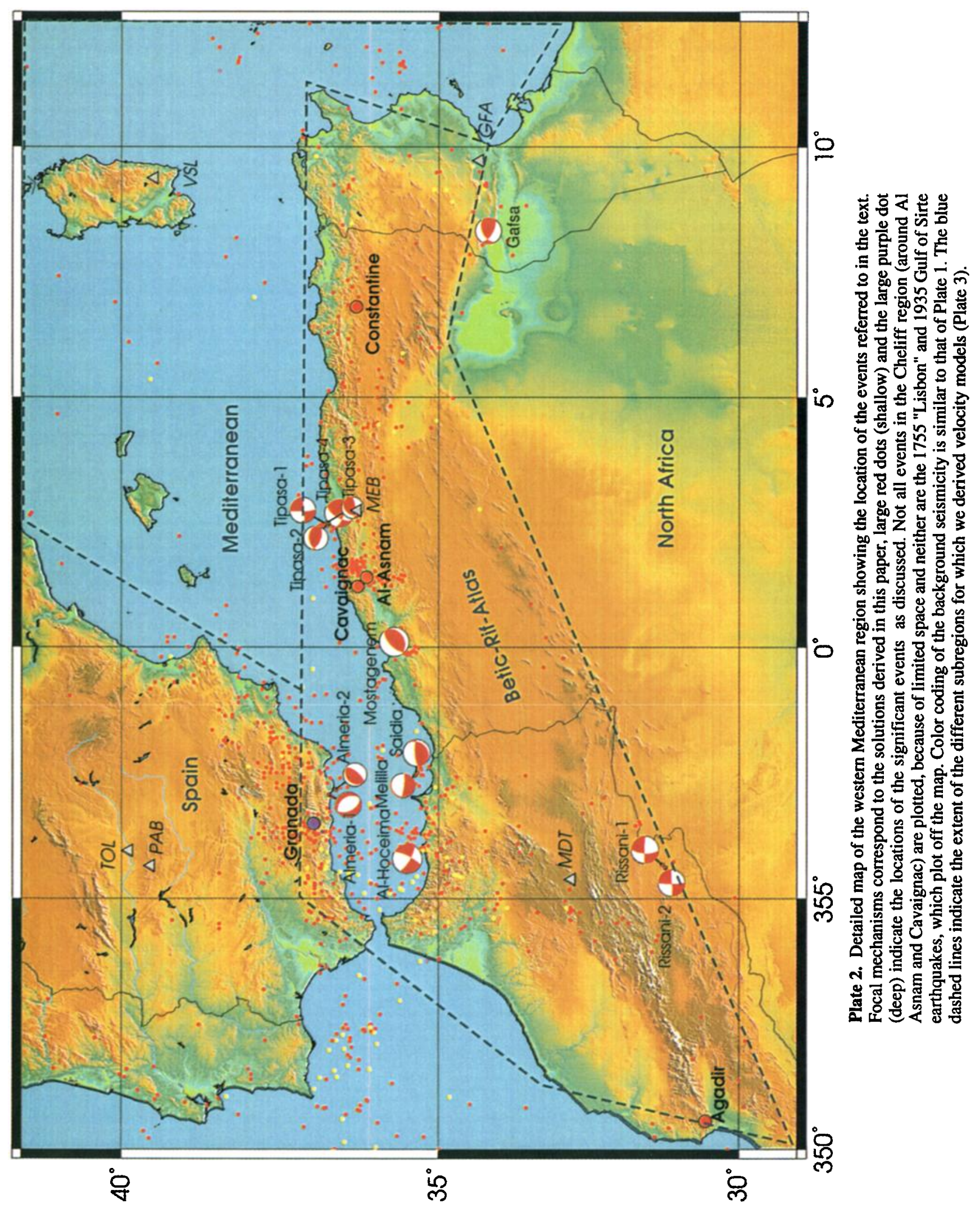


the very late Precambrian. The Hoggar plateau in southern Algeria, near the location of station Tamanrasset (TAM) has also undergone major igneous activity in the late Precambrian, as well as tertiary to present day volcanic activity [Cahen and Snelling, 1984]. Both the West-African shield as well as the Touareg shield are virtually free of any seismic activity. Finally, the Balearic basin, also called Provençal basin, which covers the major part of the western Mediterranean Sea has a young oceanic crust, created through extension during the Oligocene and Miocene [Doglioni $e t$ al., 1997].

\subsection{Historic Seismicity}

The historic seismicity of the western Mediterranean region is well documented and we will present a short overview of the most significant events in the region. The largest event to have affected the region was the 1755 "Lisbon" (M 8.7 [Johnston, 1996]) earthquake which probably occurred in the Atlantic ocean.

In North Africa, many significant earthquakes have occurred around the city of Ech-Cheliff, formerly known as Al Asnam and Orléansville. The destructive $1980 \mathrm{Al}$ Asnam earthquake $\left(M_{S}=7.3\right.$, $M_{W}=7.1$ [Deschamps et al., 1982]) has been studied extensively, and is the largest earthquake to have occurred in this region this century. Several other significant earthquakes occurred in the same general area, the Cheliff Valley [Ambraseys et al., 1991b], including the 1954 Orléansville earthquake, the 1922 Cavaignac $\left(M_{S}=\right.$ 5.9) earthquake [Aoudia and Meghraoui, 1995], and an estimated $M_{S}=6.5$ earthquake in 1858 . Farther east, there occurred a $M_{S}=$ 6.6 earthquake in 1910 [Ambraseys et al., 1991a], the 1985 Constantine earthquake ( $M_{S}=6.0$ [Deschamps et al., 1991]), and an $M$ $=7.1$ event in the eastern Gulf of Sirte in 1935. To the west, the seismicity decreases until beyond the Moroccan border where we find a band of seismicity around the Alboran Sea, the Rif Mountains and along the Atlas mountain ranges. The 1960 Agadir earthquake ( $m_{b}=5.8$ [Cherkaoui et al., 1991]), in which 12,000 people lost their lives, is one of the best known earthquakes in the region and occurred at the southwestern end of the Atlas mountains, on the border between the Atlas mountains and the Precambrian West-African shield to the south.

Across the Strait of Gibraltar the only large recorded earthquake is the deep $(z=600 \mathrm{~km}) 1954$ earthquake near Granada $(M=7.0)$ [Buforn et al., 1991]. Although the level of background seismicity is high in southern Spain, no major shallow earthquakes have been recorded this century. Nevertheless, the potential for large and damaging earthquakes is high along both coastlines of the western Mediterranean Sea, and improved source estimation capabilities can contribute significantly toward the evaluation of seismic hazard in the region.

\subsection{Seismic Structure From Previous Work}

Seismic studies of the westem Mediterranean and North Africa consist of deep seismic sounding studies [Working Group for Deep Seismic Sounding in Spain 1975-1975, 1977, hereinafter called WG77; Research Group for Lithospheric Structure under Tunisia, 1992, hereinafter RG92], surface wave group velocity studies [e.g., Hadiouche and Jobert, 1988] and tomographic studies [Zielhuis, 1992].

In a tomographic study of Africa using surface waves, Hadiouche and Jobert [1988] found that the $S V$ velocities show a sharp contrast in northern Africa between fast velocities west of the Greenwich meridian and slow velocities east of the meridian. This corresponds roughly to the boundary between the West-African craton and the Trans-Saharan Mobile Belt. Snieder [1988] and Ziel- huis [1992] found that the upper mantle below the western Mediterranean is relatively slow. Corchete et al. [1995] studied lateral variations of the $S$ velocity of the subcrustal lithosphere under the Iberian peninsula and concluded that a low-velocity channel exists throughout most of Spain at a depth of around $40-50 \mathrm{~km}$, with $S$ velocities decreasing from between 4.5 and $4.65 \mathrm{~km} / \mathrm{s}$ to 4.3 and $4.5 \mathrm{~km} / \mathrm{s}$. A similar low velocity zone was found under the Betic Cordillera from deep seismic sounding experiments (WG77).

Seber et al. [1996a] investigated teleseismic $P$ wave residuals recorded at stations in Morocco and concluded that the Rif Mountains, as well as the Alboran Sea are underlain by fast upper mantle. This contradicts low $P_{n}$ velocities found by Banda [1988]. They reconcile these differences by assuming that the thickened lithosphere under the Rif Mountains and the Alboran Sea has delaminated, so that the faster lithosphere is now overlain by slower and hotter astenospheric material. Pino and Helmberger [1997] studied waveforms at triplication distances under the western Mediterranean and inferred, among other things, the existence of a strong gradient in the seismic velocities at the top of the mantle.

\section{Data and Surface Wave Analysis}

We selected several earthquakes which were well-recorded at several stations in the region (Plate 2). Harvard [Dziewonski and Woodhouse, 1983] and MedNet [Giardini et al., 1993] centroid moment tensor (CMT) solutions were available for some of these events (Table 1), and for one event, Al Hoceima (94146), there was sufficient teleseismic body wave data available to perform a teleseismic source inversion, which we shall discuss in section 4.1. In Table 1, we also present mechanisms based on first motions, by Rueda et al. [1996], Meghraoui [1991], and Mezcua and Rueda [1997].

We can illustrate the lateral heterogeneity in the region by comparing the observed seismograms (Figure 1) at different stations for the Gafsa (Tunisia) event (92164). The stations MEB (Medea, in northern Algeria) and VSL (Villasalto, on the island of Sardinia) are at very similar epicentral distances (Figure 1a), yet their records are very different in character and the arrival times for the Rayleigh waves are quite different as well. The same holds true for the station pair TAM and TOL (Figure lb). Another striking observation is the different high-frequency content of the records. The recordings for paths that are located within North Africa (MEB and TAM) have a much stronger high-frequency content than the paths that cross the Mediterranean Sea (TOL and VSL). This suggests that the Mediterranean Sea is very effective at blocking $L g$ waves, and this effect becomes very obvious after applying a high-pass filter to the data (Figure 2). The $L g$ waves arrive at group velocities of about $3.5 \mathrm{~km} / \mathrm{s}$, which in Figure 2 is between the time marks $T_{1}$ and $\mathrm{T}_{2}$. Whereas the stations MEB and TAM show distinct $L g$ arrivals, there are no $L g$ waves discernible on the records that have crossed the Mediterranean, i.e., at TOL and VSL. As a consequence, seismic discriminants based on $L g$ observations are ineffective for waves crossing this part of the Mediterranean, and this probably holds true for most of the Mediterranean Sea.

In order to quantify the lateral heterogeneity, we first determined the group velocities to get an estimate of the velocity structure in the region. These velocities were determined using a moving window analysis, similar to the method of Landismann et al. [1969]. We present the group velocity measurements for selected events arranged by station in Figure 3. Figure 3 clearly shows that for most stations the group velocities vary significantly, except for paths to station Tamanrasset (TAM). Also plotted in Figure 3 are group velocities that we computed for our preliminary models. 
Table 1. Source Parameters of the Events Studied in This Paper

\begin{tabular}{|c|c|c|c|c|c|c|c|c|c|c|c|c|}
\hline EventId & Date & Time, UT & Latitude & Longitude & Depth & Strike & Dip & Slip & $z$ & Mw & Name & Source \\
\hline \multirow[t]{2}{*}{88305} & Oct. 31,1988 & $10: 12: 57.6$ & 36.402 & 2.682 & 10.0 & 105 & 65 & 150 & 10 & 5.7 & Tipasa & 1 \\
\hline & & & & & & 103 & 55 & 167 & & 5.6 & & 2 \\
\hline \multirow[t]{3}{*}{89302} & Oct. 29,1988 & 19:09:13.0 & 36.782 & 2.443 & 6.0 & 85 & 83 & 172 & 10 & 5.2 & Tipasa-1 & 1 \\
\hline & & & & & & 91 & 48 & 119 & & 5.9 & & 2 \\
\hline & & & & & & 256 & 74 & 93 & & & & 3 \\
\hline \multirow[t]{2}{*}{90040} & Feb. 2, 1990 & $09: 31: 47.6$ & 36.775 & 2.481 & 12.0 & -101 & 39 & 63 & 5 & 4.8 & Tipasa-2 & 1 \\
\hline & & & & & & 49 & 19 & 95 & & 5.2 & & 2 \\
\hline 90102 & April 121990 & $22: 47: 53.2$ & 36.792 & 2.493 & 14.0 & -150 & 34 & 38 & 10 & 4.3 & Tipasa-3 & 1 \\
\hline \multirow[t]{2}{*}{92164} & June 12,1992 & $19: 16: 45.7$ & 34.197 & 8.328 & 19.0 & -118 & 48 & 43 & 14 & 5.2 & Gafsa & 1 \\
\hline & & & & & & 82 & 36 & 114 & & 5.2 & & 2 \\
\hline \multirow[t]{2}{*}{92297} & Oct. 23, 1992 & $09: 11: 05.5$ & 31.294 & -4.325 & 5.0 & -179 & 68 & -4 & 19 & 5.5 & Rissani-1 & 1 \\
\hline & & & & & & -173 & 69 & 12 & & 5.5 & & 2 \\
\hline \multirow[t]{2}{*}{92304} & Oct. 30,1992 & $10: 43: 55.8$ & 31.246 & -4.381 & 8.0 & 88 & 89 & 173 & 17 & 5.4 & Rissani-2 & 1 \\
\hline & & & & & & 90 & 72 & 176 & & 5.6 & & 2 \\
\hline \multirow[t]{2}{*}{92356} & Dec.21, 1992 & 09:02:57.2 & 35.386 & -2.548 & 8.0 & -136 & 10 & -142 & 10 & 4.9 & Melilla & 1 \\
\hline & & & & & & -113 & 28 & 133 & & & & 4 \\
\hline \multirow[t]{2}{*}{93143} & May 5, 1993 & $07: 40: 57.0$ & 35.356 & -2.504 & 27.0 & -94 & 73 & 103 & 9 & 5.3 & Saidia & 1 \\
\hline & & & & & & -52 & 84 & 179 & & & & 4 \\
\hline \multirow[t]{3}{*}{93357} & Dec. 23, 1993 & $14: 22: 35.1$ & 36.756 & -2.937 & 27.0 & 151 & 52 & -87 & 6 & 5.1 & Almeria & 1 \\
\hline & & & & & & -2.5 & 43 & -88 & & 5.2 & & 2 \\
\hline & & & & & & 188 & 44 & -29 & 8 & & & 5 \\
\hline \multirow[t]{2}{*}{94004} & Jan. 4, 1994 & 08:03:15.8 & 36.651 & -2.822 & 22.0 & 220 & 25 & 90 & 15 & 4.7 & Almeria-2 & 1 \\
\hline & & & & & & 274 & 63 & 52 & & & & 5 \\
\hline \multirow[t]{3}{*}{94146} & May 26, 1994 & $08: 26: 52.4$ & 35.308 & -4.105 & 10.0 & 120 & 76 & -166 & 10 & 5.8 & Al-Hoceima & 1 \\
\hline & & & & & & 112 & 48 & -173 & & 5.9 & & 2 \\
\hline & & & & & & 315 & 74 & -168 & 3 & & & 4 \\
\hline \multirow[t]{2}{*}{94230} & Aug. 18, 1994 & $01: 13: 05.7$ & 35.520 & 0.106 & 9.0 & -134 & 60 & 81 & 8 & 5.8 & Mostagenem & 1 \\
\hline & & & & & & -119 & 68 & 98 & & 5.8 & & 2 \\
\hline
\end{tabular}

Location and origin time are from the ISC catalogue. Focal mechanism are from the following sources: (1) this study, (2) Harvard CMT, (3) Meghraoui [1991], (4) Mezcua and Rueda [1997], and (5) Rueda et al. [1996].

Group velocities measured at station PAB (Figure 3a) show considerable variations, even at longer periods. Even though the path from the events in southern Spain is relatively short and therefore has poor resolution at longer periods ( $>50 \mathrm{~s}$ ), we can still conclude that the group velocities are substantially higher than those observed for paths from North Africa.

At VSL (Figure 3b) the group velocities are invariably low and show a large variation. However, the low group velocity maxima suggest that upper mantle velocities are low for all paths. The large variations at periods shorter than $40 \mathrm{~s}$ are mostly due to the upper crustal structure. The one purely oceanic path, from Almeria to VSL, shows a very smooth dispersion curve down to $10 \mathrm{~s}$ and indicates that the crust is relatively thin and that the upper mantle velocities are low.

As already mentioned, the group velocities recorded at station TAM (Figure 3c) in southern Algeria only diverge at periods shorter than $20 \mathrm{~s}$. We can therefore assume that the Touareg shield region, which represents the largest section of these paths by far, has a homogeneous upper mantle and lower and middle crust. Variations in sedimentary cover can explain the difference in group velocities at short periods. The records at TAM (Figure 1b) are indeed very clean and show little evidence for complex structures.

In contrast, for paths to station MEB (Figure 3d), we find very strong variations in group velocities. We suspect that in this case multipathing may be a significant factor on the measurements, since MEB is located close to the transition between the African continental crust and the Mediterranean oceanic crust. The records at MEB (e.g., Figure la) indeed look very complicated with very strong ringing in the $P_{n l}$ wave train, which may be caused by low upper crustal velocities but also by scattering away from the great circle path. Also, as mentioned earlier, there are several very deep sedimentary basins located along the north coast of Algeria [Meghraoui et al., 1996], close to the station, which can have a large influence on the surface wave velocities.

\section{Preliminary Structure}

Based on surface wave group velocity measurements presented above we have constructed velocity models for the different parts of the region (Plate 3), namely North Africa, the Mediterranean, the 


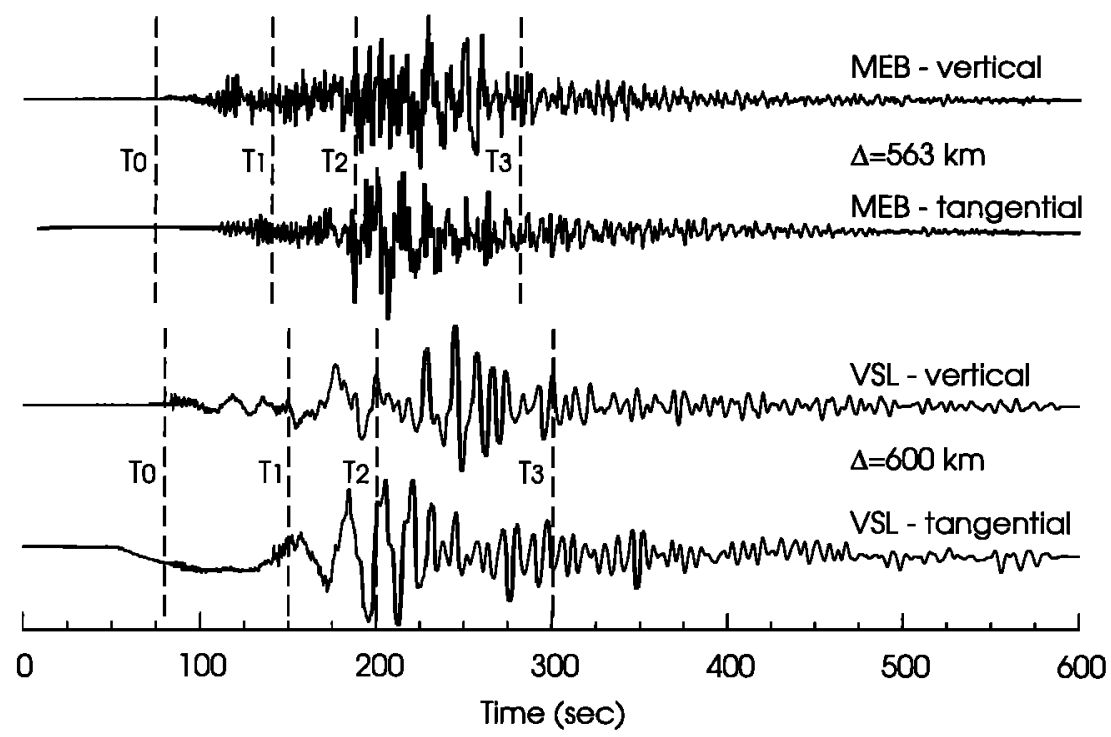

Figure 1a. Broadband displacement seismograms for the Gafsa (Tunisia) event recorded at stations MEB and VSL. $T_{0}$ - arrival time corresponding to a group velocity of $7.5 \mathrm{~km} / \mathrm{s} ; \mathrm{T}_{1}, 4 \mathrm{~km} / \mathrm{s} ; \mathrm{T}_{2}, 3 \mathrm{~km} / \mathrm{s} ;$ and $\mathrm{T}_{3}, 2 \mathrm{~km} / \mathrm{s}$.

Betic-Rif-Tell region, and Spain. For Algeria we found a crustal thickness of $37 \mathrm{~km}$ and little lateral variation except for the coastal regions. We need to perform additional modeling to determine the finer structure in that area, especially with regards to paths to station MEB. The low upper mantle velocities that we found for Algeria are consistent with the observation of Hadiouche and Jobert [1988].

For the Mediterranean we found a crustal thickness of $20 \mathrm{~km}$, similar to crustal depths obtained from refraction profiles (RG92), but we could not fit the Love and Rayleigh wave data with a single model, and our preliminary model is different for Love and Rayleigh waves. However, the generally low upper mantle velocities in this region are consistent with tomographic models of Snieder [1988] and Zielhuis [1992]. For southern Spain we found a crustal thickness of $28 \mathrm{~km}$ and higher upper mantle velocities, which are consistent with the results of deep seismic sounding (WG77).

The Moho depths are not always consistent with those compiled by the Cornell University Middle East and North Africa Project
[Barazangi et al., 1996]: for example, our crustal thickness for Spain is significantly smaller than the compilation's depth, and from dispersion observations it seems that the depth under the Algerian coastal region is increased relative to the depth under the North African shield.

\section{1. $\mathbf{P}_{\mathrm{nl}}$ Propagation}

The $P_{n l}$ wave train is important in seismic source estimation studies [e.g., Zhao and Helmberger, 1994] as well for seismic discrimination studies [Woods and Helmberger, 1997], and it is therefore important to calibrate this phase, especially in regions like the Mediterranean where $L g$ blockage is strong. We modeled the $P_{n l}$ arrivals using generalized ray theory [Helmberger, 1983]. In Plate 4 we show the fit of the $P_{n l}$ wave for several events along the North African coast recorded at station PAB. The waveforms seem quite stable for the different paths, but the travel times change with path. From these modeling efforts, we conclude that both the $P_{n}$

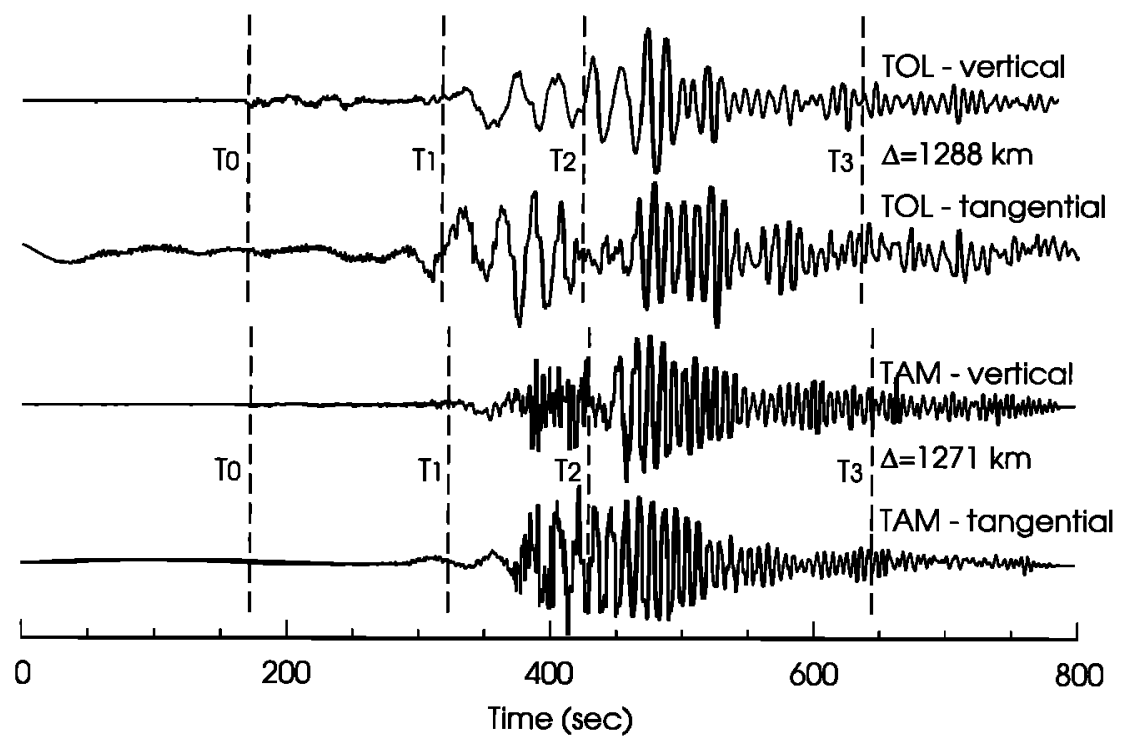

Figure 1b. Similar to Figure la for stations TOL and TAM 


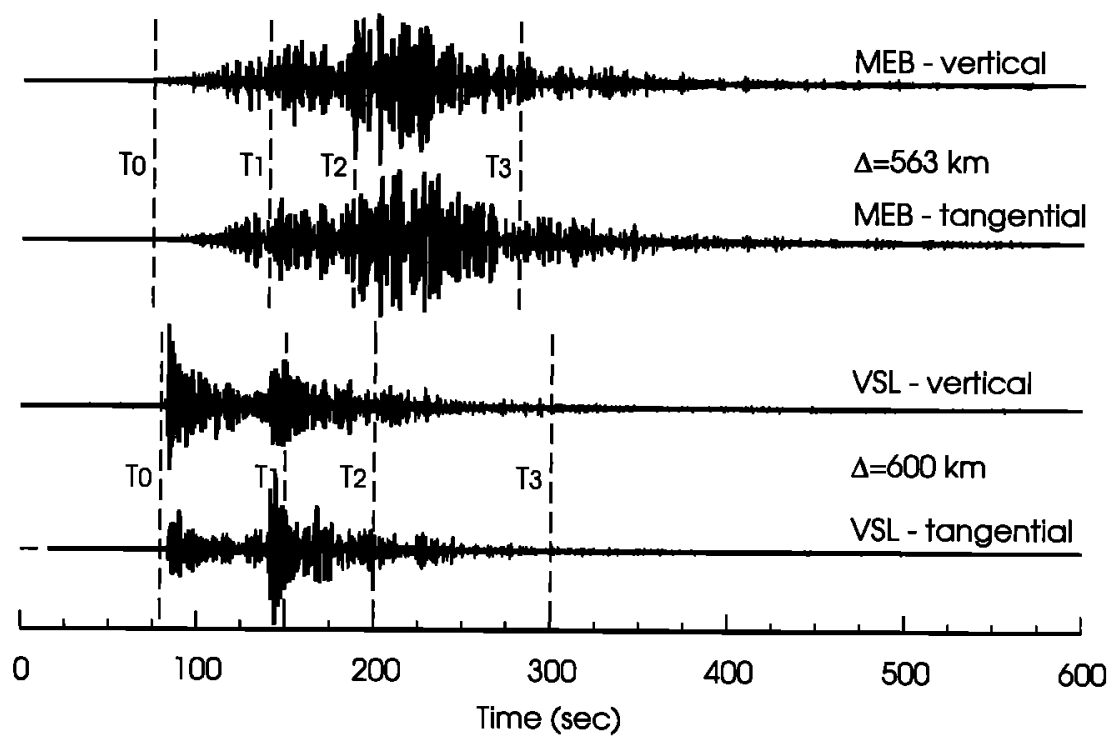

Figure 2a. High-passed ( $\mathrm{T}<2 \mathrm{~s}$ ) displacement seismograms for the Gafsa event recorded at stations MEB and VSL. $T_{0}$, arrival time corresponding to a group velocity of $7.5 \mathrm{~km} / \mathrm{sec}, T_{1}, 4 \mathrm{~km} / \mathrm{s} ; \mathrm{T}_{2},-3 \mathrm{~km} / \mathrm{s} ;$ and $\mathrm{T}_{3}, 2 \mathrm{~km} / \mathrm{s}$. Note the lack of $L g$ energy (between $T_{1}$ and $T_{2}$ ) at station VSL.

velocity as well as the average crustal $P$ velocity under the Mediterranean increase from west to east, with the lowest velocities occurring under the Alboran Sea. This is consistent with observations of Banda [1988].

$P_{n l}$ observations from the Rissani events recorded at station MEB and VSL (Figure 4), which are located at similar azimuths but different distances (860 and $1540 \mathrm{~km}$, respectively) show that the $P$ waves at station VSL are very sharp and distinctive. This feature is best explained by a gradient at the top of the mantle (Plate 5) which makes the $P$ wave appear more as a turning ray instead of a headwave. Therefore the $P, p P$ and $s P$ phases appear distinctively at these distances as they do at teleseismic distances. A similar effect may be occurring in the observed records of the Gafsa event (Figure 1a) at VSL, where the $P_{n}$ and $S_{n}$ arrivals are quite distinct even at high frequencies (Figure 2a). Pino and Helmberger [1997] found a gradient in the upper mantle based on observations of paths that cross the region around VSL, although their gradient is not sufficient to explain the distinct pulses that we observed (Plate 5). We have not yet been able to establish how pervasive this effect is for other paths from North Africa, but with more data from MedNet being released, it may be possible to calibrate and use these characteristics for depth determinations.

\subsection{Regionalization}

From our observations it is clear that regionalization is required in order to study events in this region. In this section we present a simple but effective way to apply a regionalized model, along the line of earlier works like Dziewonski and Steim [1982], to compute synthetic waveforms.

Lateral heterogeneity plays a significant role in source inversion studies, especially if the source-receiver paths extend beyond sev-

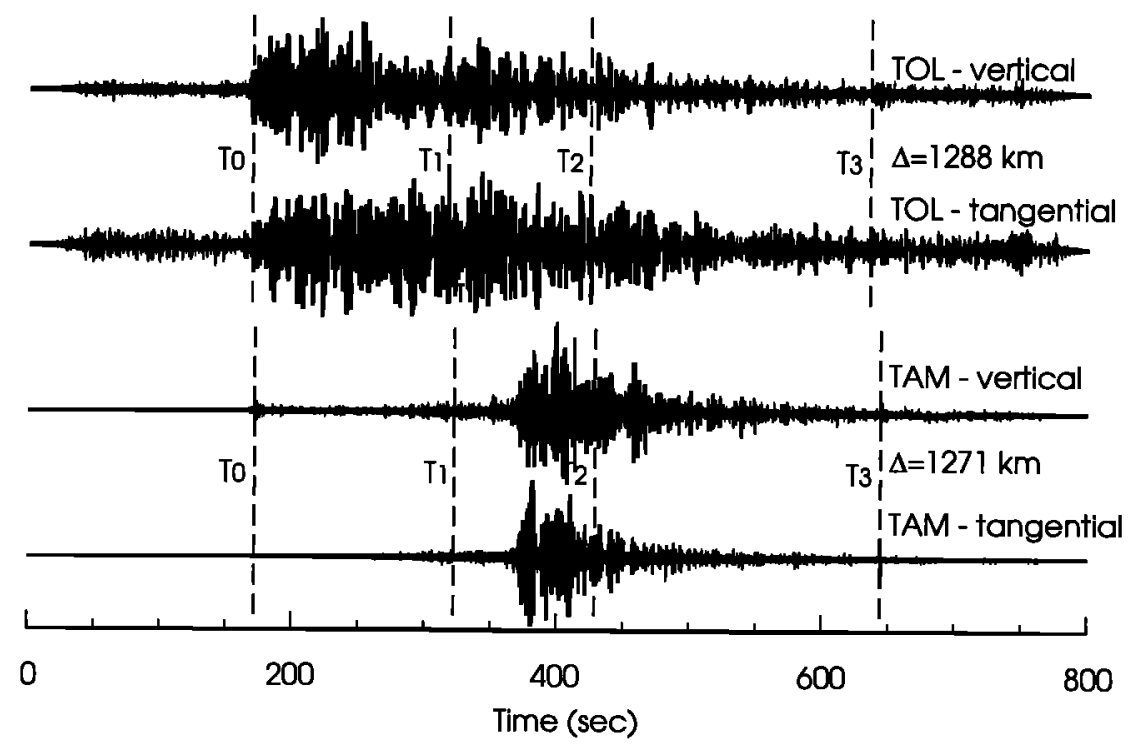

Figure 2b. Same as Figure 2a for stations TOL and TAM. Note that the $L g$ energy is missing from the recording at TOL. 

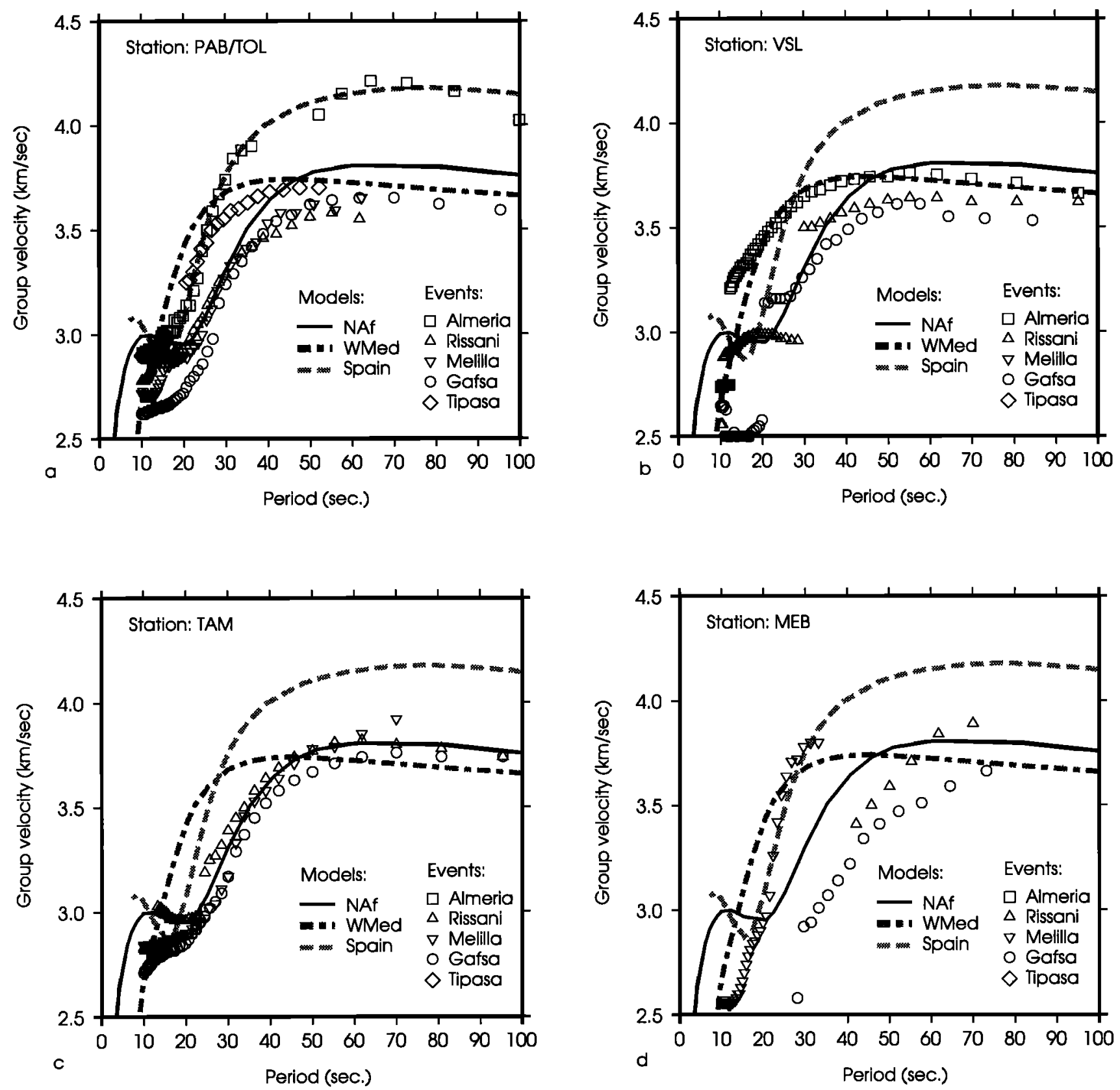

Figure 3. Group velocity measurements for selected source-receiver pairs, plotted per station. (a) observations at PAB/TOL, (b) VSL, (c) TAM, and (d) MEB. The curves correspond to group velocities for the different preliminary models (Plate 3).

eral hundred kilometers. However, for larger distances and heterogeneous media, even if simple time shifts are allowed, it is difficult to use the full waveforms because different phases are sensitive to different parts of the structure and therefore need different time corrections. Zhao and Helmberger [1994] solved this problem for weakly heterogeneous cases by splitting the waveforms up in a $P_{n l}$ part and a surface wave part and allowing these to shift in time independently. For paths through relatively homogenous media, like the Hindu Kush [Zhu et al., 1997], this method yields good results. However, in strongly heterogenous media, like the present study region, this solution is not sufficient. Because of the radically different dispersive characteristics of the surface waves for different regions, the shape of the surface wave train can become very different (e.g., ringing versus an impulsive surface wave), and this effect can not be synthesized by using a simple time shift. Thio and Kanamori [1995] applied a regionalized phase velocity model for moment tensor inversions in southern California using short-period surface waves. This method is based on the fact that to a first order, perturbations from a homogeneous velocity model can be accounted for by perturbations in the phase velocity and it is widely used in global surface wave studies [e.g., Nakanishi and Kanamori, 1982]. If we approximate the fundamental mode seismogram as

$$
u(\Delta, t)=\sum_{n=0}^{N} A_{n} e^{\imath\left(k_{n} \Delta-\omega_{n} t\right)}=\sum A_{n} e^{\imath k_{n}\left(\Delta-c_{n} t\right)}
$$

where $u$ is the displacement at distance $\Delta$ and at time $t, A_{n}$ is the 


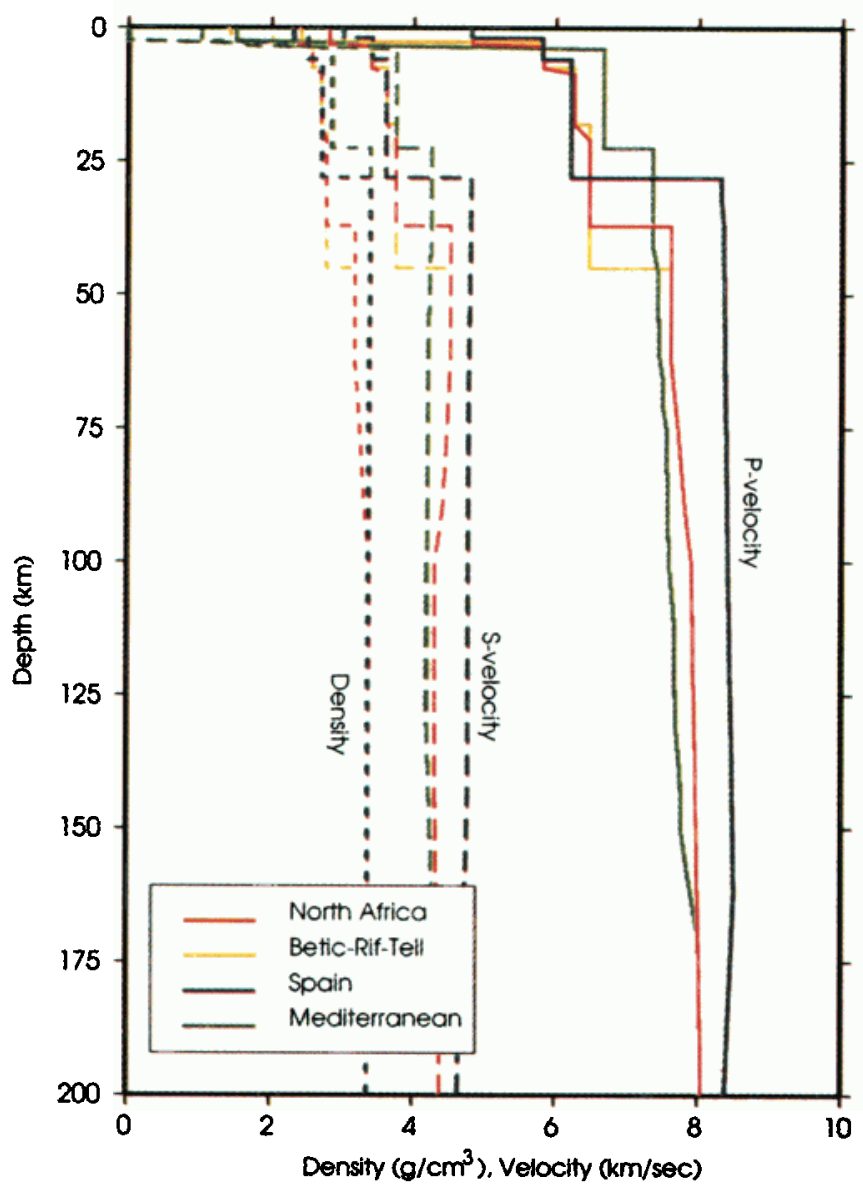

Plate 3. Regionalized velocity models used to compute the group velocities in Figure 3 and the Green's functions for the surface wave part in the hybrid inversion presented in Section 4.2.

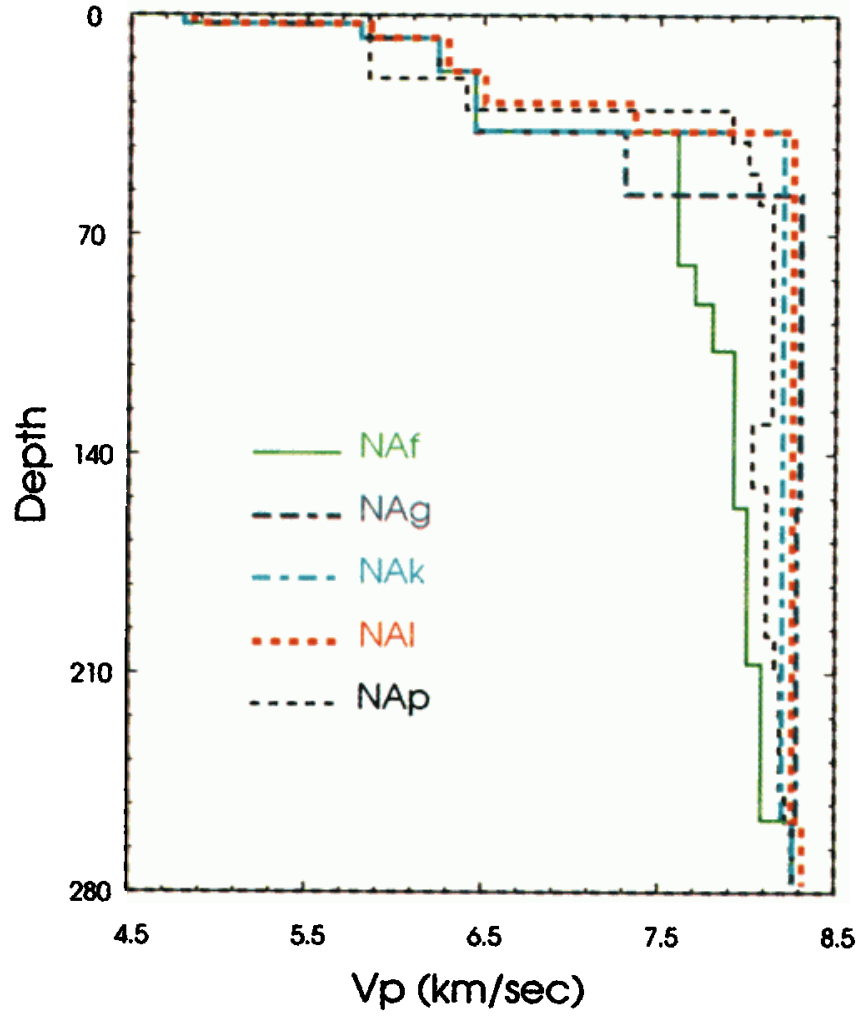

Plate 5. Velocity models used in the synthetic calculations of Figure 4. NAf is the North Africa model determined using the surface waves; NAg, NAk, and NAl are trial-and-error models without a gradient at the top of the mantle; and model NAp is the model of Pino and Helmberger [1997].

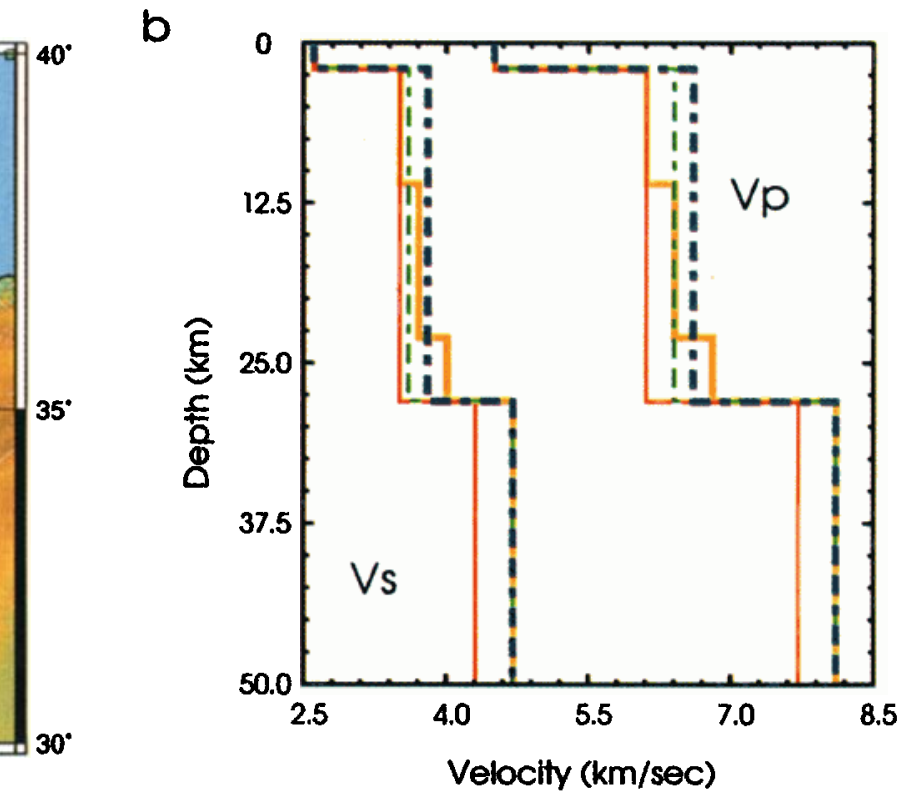

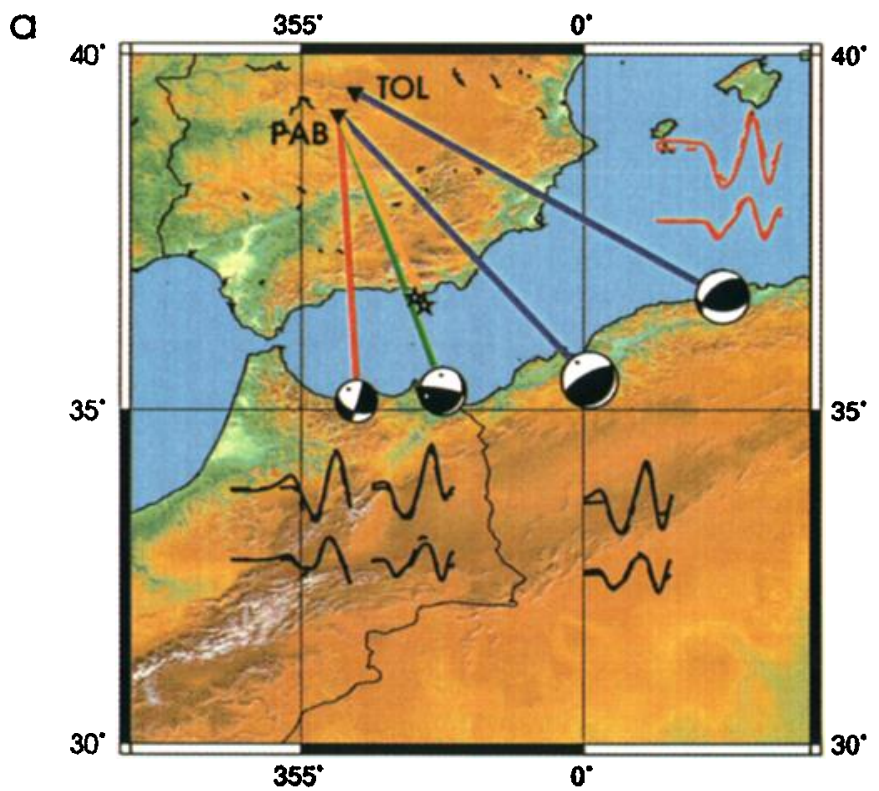

Plate 4. (a) $P_{n t}$ paths from various events to station TOL/PAB and (b) velocity models used to model these paths. The observed $P_{n l}$ waveforms are overlain with the synthetic waveforms (dashed lines); the top traces are vertical; bottom traces are radial components. The colors of the paths correspond to the colors for the velocity models. Note that slower crustal velocities are used for the events to the west. The star refers to the Almeria event shown in Figure 13. 

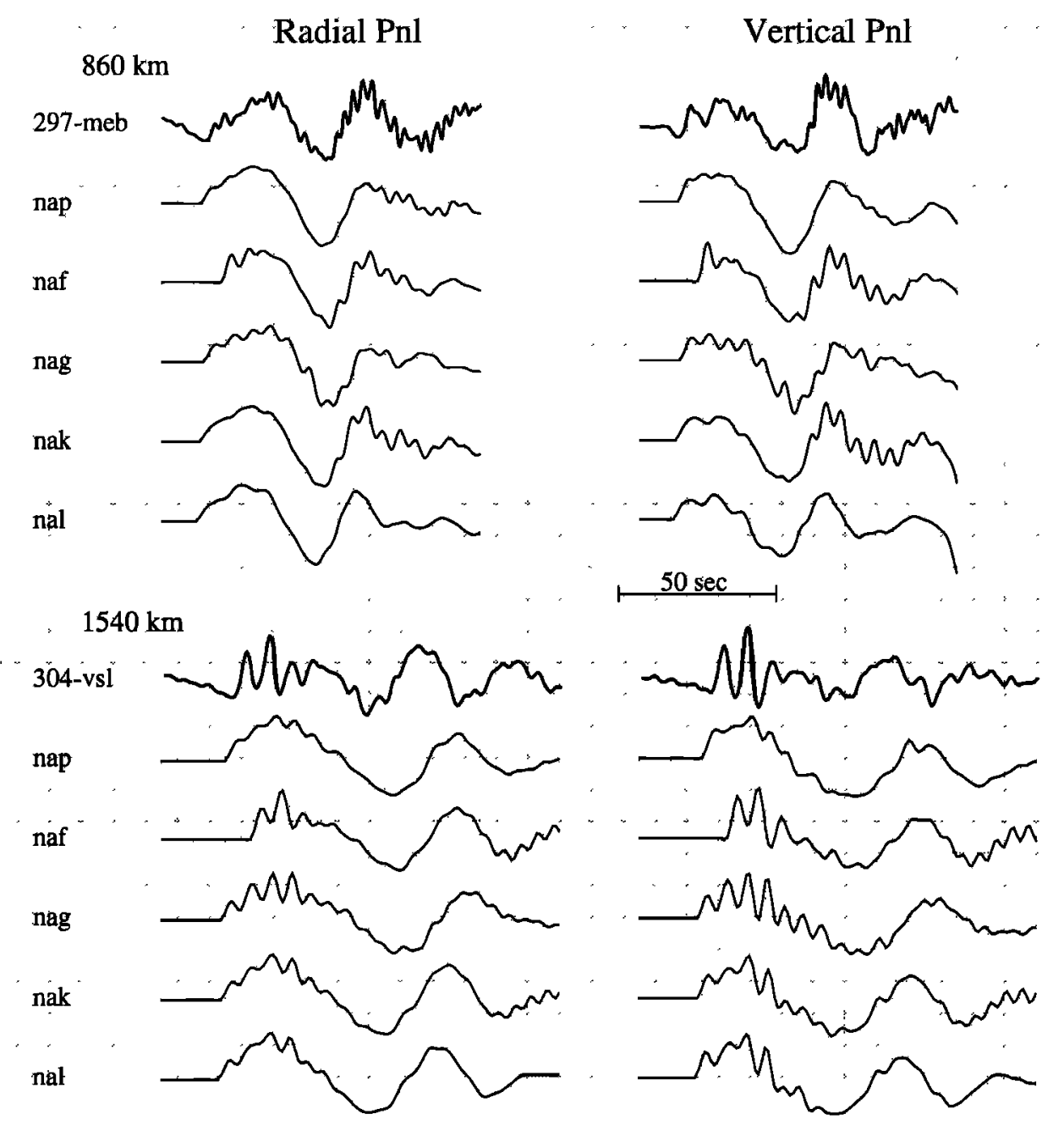

Figure 4. Comparison of a series of $P$ wave velocity models used in modeling the crustal-guided $P_{l}$ waves from the Rissani 1 earthquake recorded at (top) MEB and (bottom) VSL. These stations are located at similar azimuths from the event. Both data and synthetics are low-pass filtered with a corner frequency of $0.2 \mathrm{~Hz}$. Note that these models differ mainly in the crust-mantle transition, which controls the $P_{l}$ wave train in the frequency band shown. Data and synthetics are aligned in absolute time. The seismograms are scaled according to their largest amplitude.

excitation function for mode $n$, including the source mechanism and geometrical spreading, then to a first order the effect of a change in phase velocity will manifest itself only in the phase function; that is, we can suffice by replacing $c$, which is the phasevelocity computed for the original one-dimensional (1-D) model, with $1 / \bar{p}$ where $\bar{p}$ is the path-averaged phase slowness calculated from our regionalized velocity model. It should be noted that this method is not restricted to the calculation of fundamental mode surface waves but can easily incorporate higher modes as well, so that body waves could be included if necessary. However, in general, lateral heterogeneity is most pronounced in the upper crust, and this has the largest effect on fundamental mode surface waves. This method may not be valid in cases where multipathing becomes dominant, e.g., at larger distances relative to the wavelength of interest. In our case, we see little evidence of multipathing for periods longer than 10-15 s.

This approach was used by Thio and Kanamori [1995] to study the effect of lateral heterogeneity in southern California. In Figure 5 we present synthetic Rayleigh waves calculated for a suite of mixed paths, starting with a purely Spanish path and sequencing through a range of mixed paths with increasing contributions by the Mediterranean model to a purely Mediterranean path. It is clear from Figure 5 that the change of models has a very strong influence, not only on the overall arrival time of the Rayleigh waves but also on the shape of the Rayleigh wave train.

\section{Source Mechanisms}

\subsection{Surface Wave Solutions}

Using the preliminary structure obtained above from the surface wave group velocity we proceeded to calculate phase velocities for the different regions, which we then used to perform source inversion using intermediate period (20-80 s) surface waves using the method of Thio and Kanamori [1995]. In this method we determine the complex spectra of a seismogram windowed so that it includes the fundamental mode Love and Rayleigh waves only, and we correct the spectra for propagation effects. These corrected spectra represent our estimate of the spectra at the source which we invert for the source parameters (Figure 6). The optimum depth is deter- 


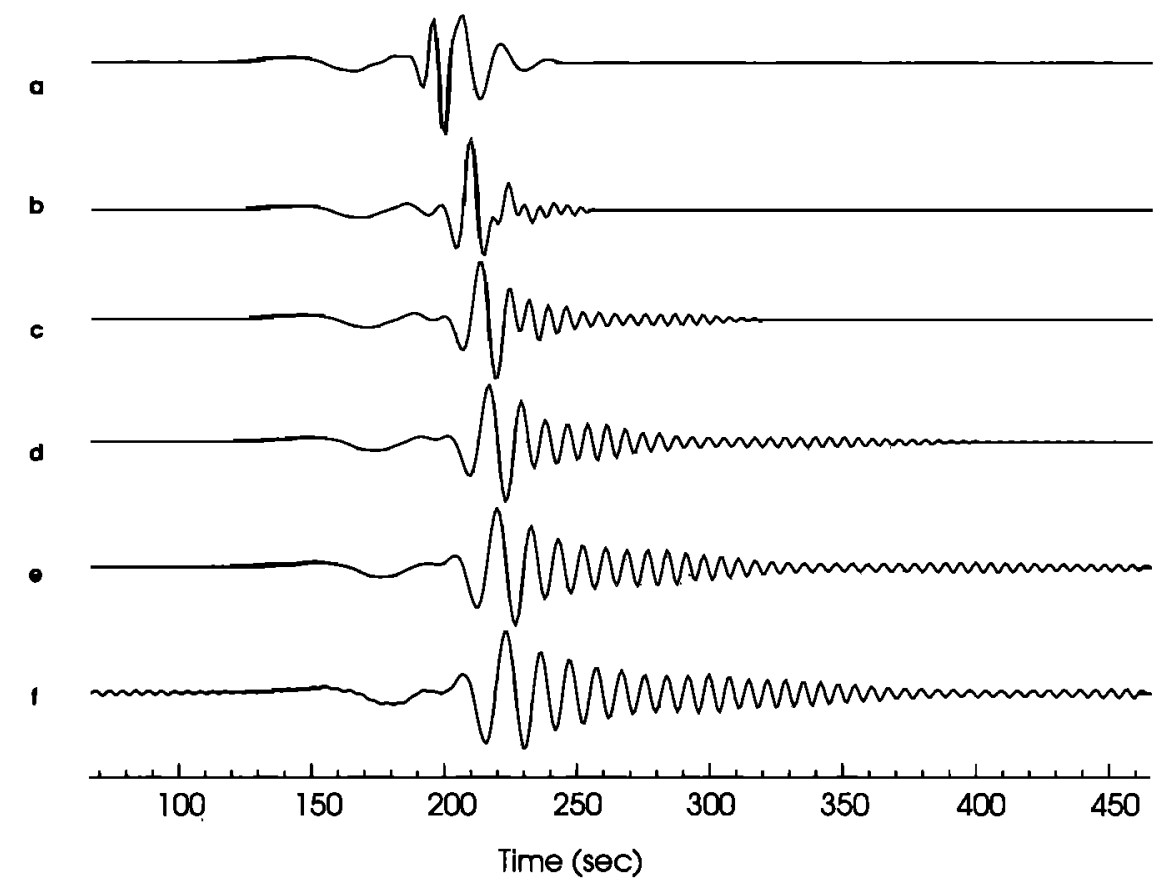

Figure 5. Vertical component Rayleigh waves computed using the mixed path approach for different ratios between a purely Spanish path and a purely Mediterranean path. (a) $100 \%$ Spanish path, (b) $80 \%$ Spanish $/ 20 \%$ Mediterranean, (c) $60 \% / 40 \%$, (d) $40 \% / 60 \%$, (e) $20 \% / 80 \%$ and (f) $0 \% / 100 \%$ (a purely Mediterrarean Sea path).

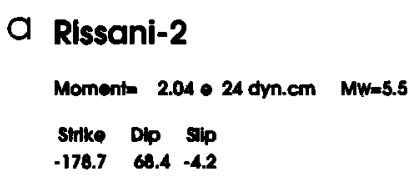

b

Love
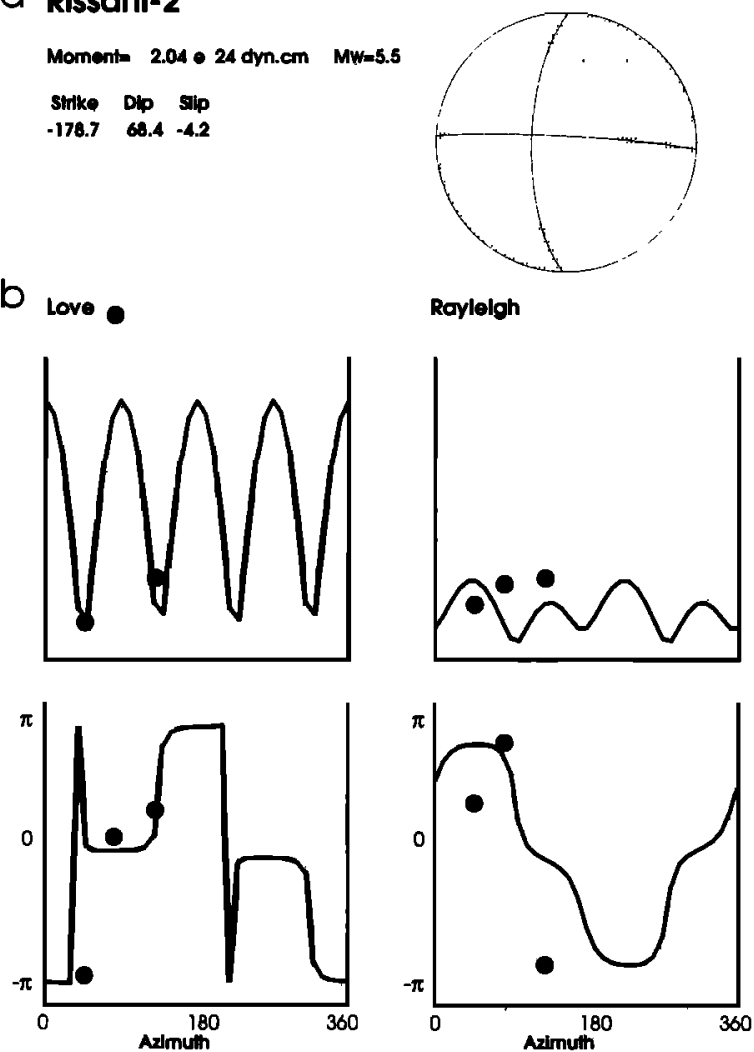

Figure 6. (a) Moment tensor solution for the Rissani 2 event. (b)The comparison between the synthetic radiation pattern and the observed spectra at $30 \mathrm{~s}$. (left) The Love wave (top) amplitude and (bottom) phase spectra, and (right) the Rayleigh wave spectra. mined by inverting for a whole range of depths (Figure 7) and choosing the one which results in the largest variance reduction (Figure 7c).

For all events we had at least three stations available which proved to be sufficient to obtain stable solutions for all events (Table 1). These solutions are consistent with the Harvard and MedNet CMT solutions, but all these solutions have difficulty with resolving depth.

In most cases, the teleseismic body wave data for these events were too small in amplitude to be useful for source parameter estimation. However, for the Rissani events (Figure 8) we could observe depth phases at some stations. Based on these recorded depth phases, we found a depth of around $20 \mathrm{~km}$ for the Rissani events (Figure 8). This is consistent with the depths that we found using the regional surface waves $(\sim 18 \mathrm{~km})$ but is substantially deeper than the depths reported in the International Seismological Centre (ISC) bulletin $(8 \mathrm{~km})$.

For the Al Hoceima event (Figure 9), we were able to collect sufficient data to carry out a teleseismic body wave inversion. We collected worldwide broadband recordings from the Incorporated Research Institutions for Seismology (IRIS), International Deployment of Accelerometers (IDA) and Geoscope networks, and after the selection of records, we were left with $18 P$ and $S$ waves with reasonable signal-to-noise ratios (Figure 9). The traces were deconvolved to displacement and we used the inversion procedure of Kikuchi and Kanamori [1991] to determine the mechanism, size, and depth. This method uses synthetic Green's functions and inverts for the best fitting solution in terms of depth, location, and mechanism. We constrained the depth to be within a range of 5 to $20 \mathrm{~km}$, with a grid interval of $5 \mathrm{~km}$. As source-time function, we chose a triangular function with a half width of $0.5 \mathrm{~s}$. The results are shown in Figure 9, and we found a strike-slip mechanism with a depth of $10 \mathrm{~km}$. This mechanism would be consistent with movement along a local fault system [Medina, 1995] and is quite similar 

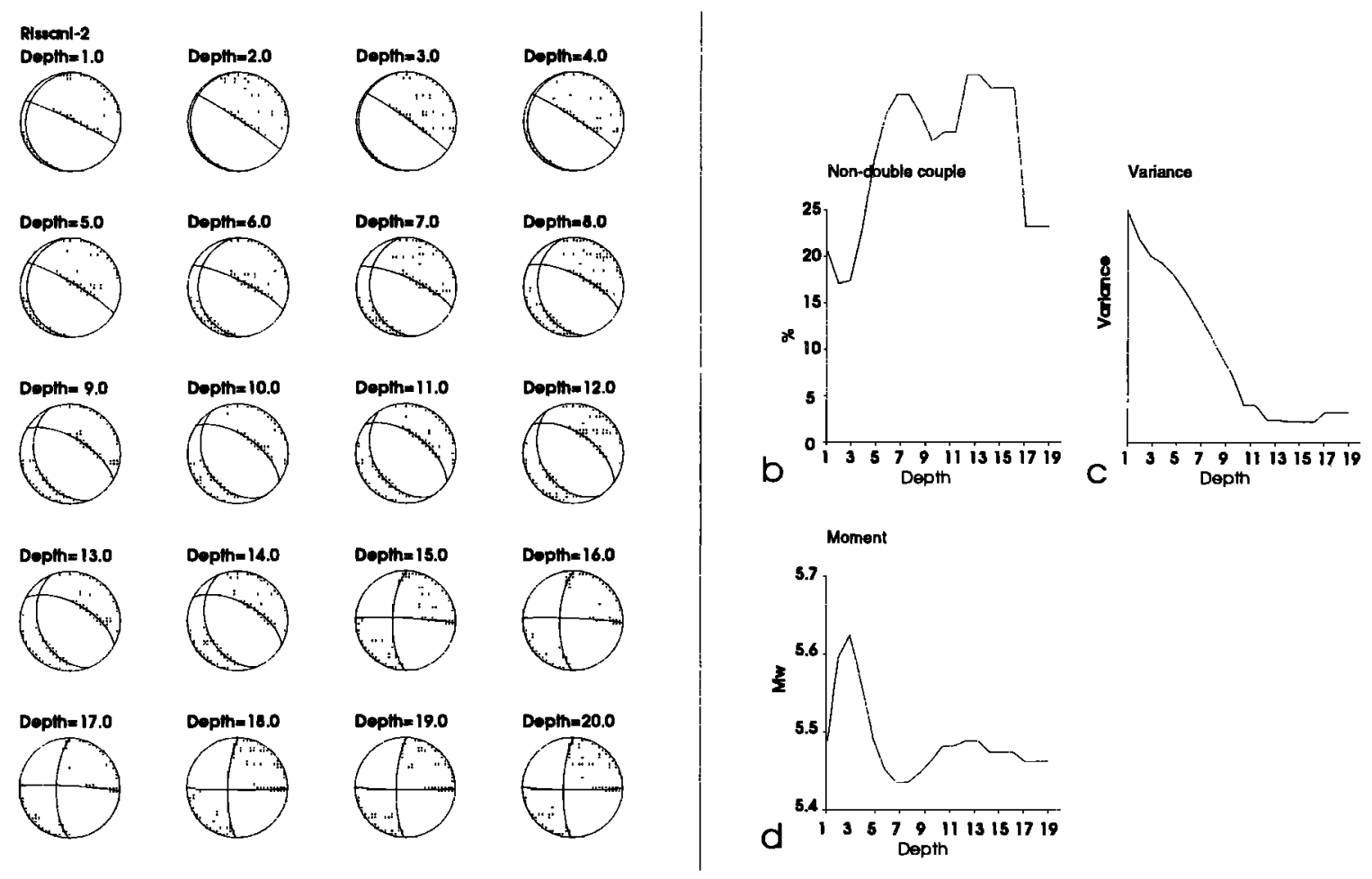

Figure 7. Dependence on depth of the moment tensor solution based on short-period surface waves. (a) Dependence of the mechanisms on depth, (b) nondouble component, (c) variance, and (d) moment.

to the Harvard CMT solution. Our solution is primarily determined by the $S H$ waves, since many of the $P$ waves are very noisy. The teleseismic $P$ waves are quite marginal for an event of this size $\left(M_{W}\right.$ $=5.8$ ), which may be due to effects of complex local structure. This means that we have to rely more heavily on regional data especially for smaller events and on data from triplication distances $\left(<30^{\circ}\right)$ that are not included in this inversion. However, in order to use these data we have to determine better calibrations for these distances, which correspond to upper mantle depths.

\subsection{Source Estimation Using Whole Waveforms}

A disadvantage of using only surface waves in source estimation studies is that the results are poorly constrained if not enough sta-

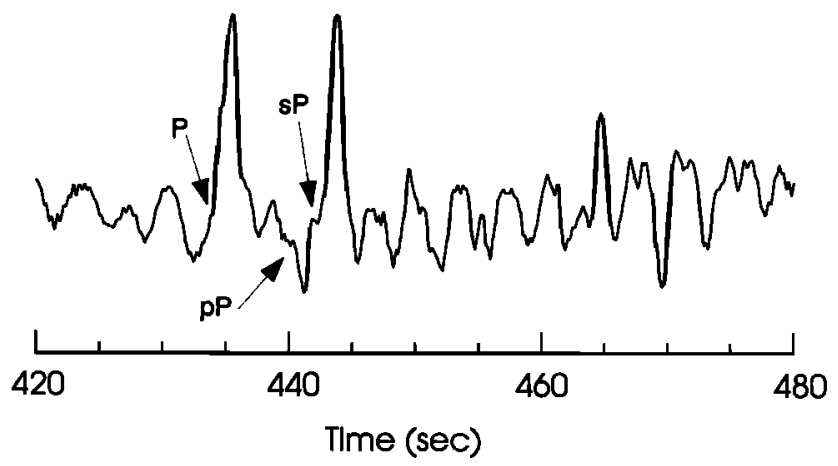

Figure 8. Teleseismic $P$ wave recording at station $O B N$ for the Rissani 1 event. Distance is $34.4^{\circ}$, and the separations between $P$, $p P$, and $s P$ correspond to a depth of $20-21 \mathrm{~km}$ (using the IASPEI95 model). tions are available. This problem becomes acute for smaller events $\left(M_{W}<5\right)$, for which often only one or two stations are available, or if only few stations in the region contribute to the monitoring system. In these cases it is necessary to use as much of the waveforms recorded as possible.

In mildly heterogenous regions like the Hindu-Kush, Zhu et al. [1997] have successfully applied the method of Zhao and Helmberger [1994] for source estimation purposes using two stations. We have applied this method to data from the present study region and in Figure 10 we present the results for the Almeria event (93356) in southern Spain using a single station (PAB). The result is compatible with the moment tensor solutions, and we obtain a very satisfactory waveform fit using a simple 1-D model. However, this model does not work satisfactorily for paths that cross the Mediterranean, especially for the surface waves as is expected from our previous sections. An example of this is presented in Figure 11, where we show the inversion result for the Gafsa event using the method of Zhao and Helmberger [1994] using a single 1-D model for all stations. The waveform fits are very poor at all stations and this solution is clearly not acceptable. Although it is possible to construct separate 1-D models to match the observed seismograms for every station-receiver pair, this is not a satisfactory solution. In most cases, the effect of lateral heterogeneity on the $P_{n l}$ waveforms consists merely of a shift in absolute time, whereas the surface waves, as mentioned earlier, can have completely different waveforms depending on the structure.

Since the surface waves and the body waves are already conveniently separated in the method of Zhao and Helmberger [1994] it is very straightforward to adapt their method for a more heterogeneous region. The only modification that we made is that we use 


\section{Al Hoceima}
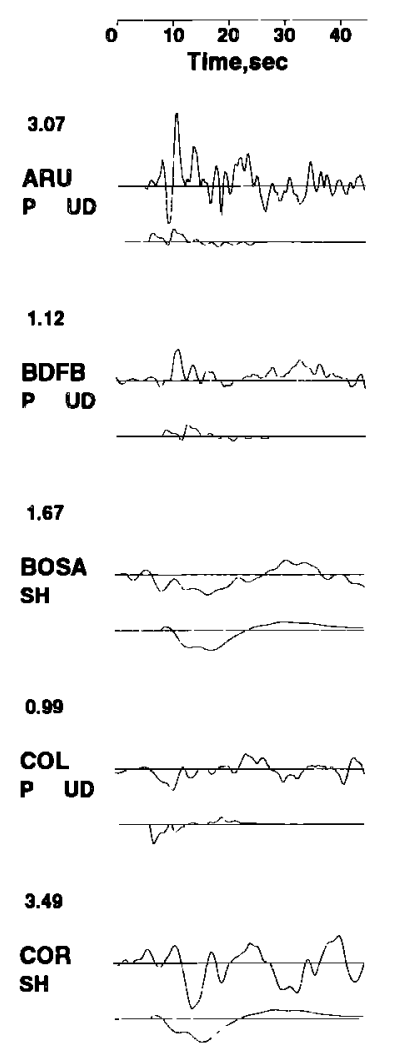
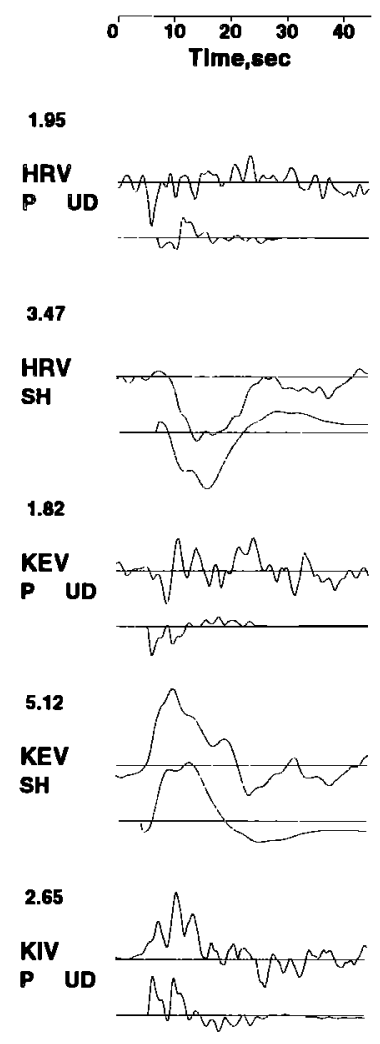
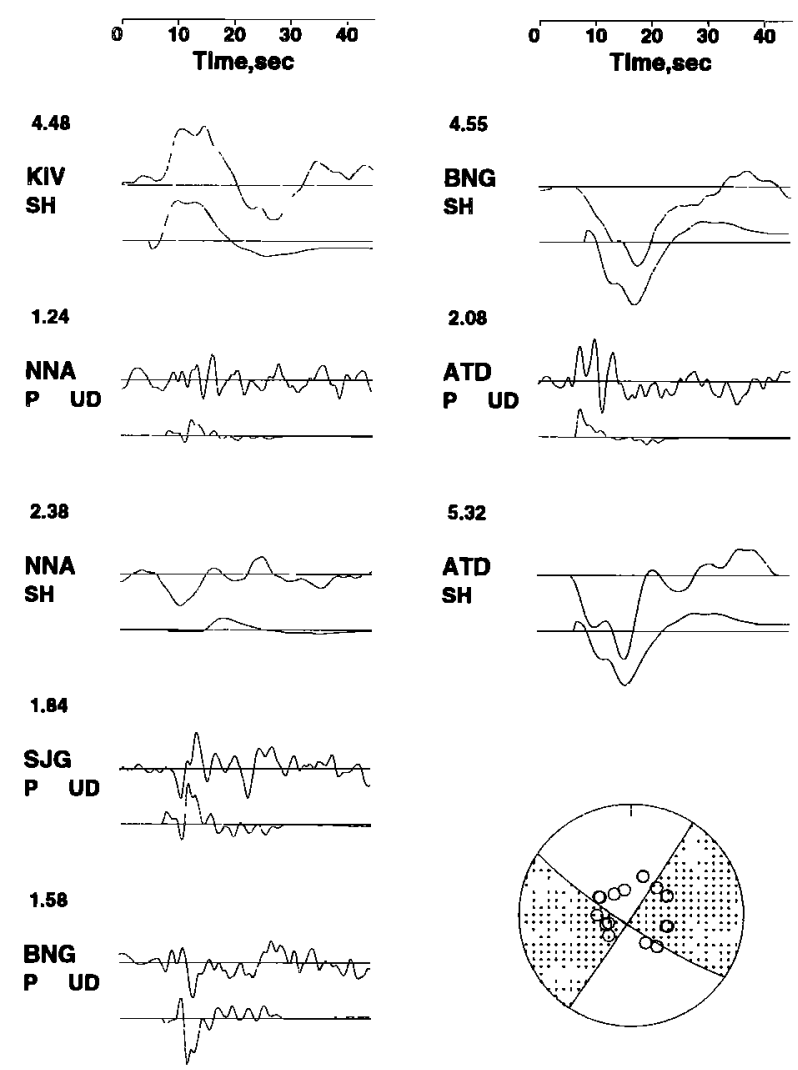

Figure 9. Observed teleseismic body waves (top traces) for the Al Hoceima event and synthetic seismograms corresponding to our solution (bottom right). $P$, vertical $P$ waves, $S H, S H$ waves. The maximum amplitudes are given in the upper left corner of every pair of traces, in microns.

the mixed path normal mode method with the regionalized phase velocity models (Plate 2), which we described earlier, to calculate the Green's functions for the surface wave part of the wave train instead of using the conventional methods of calculating body waves like ray theory.

\section{Station PAB, M0=4.6e23 dyne.cm LP3090}
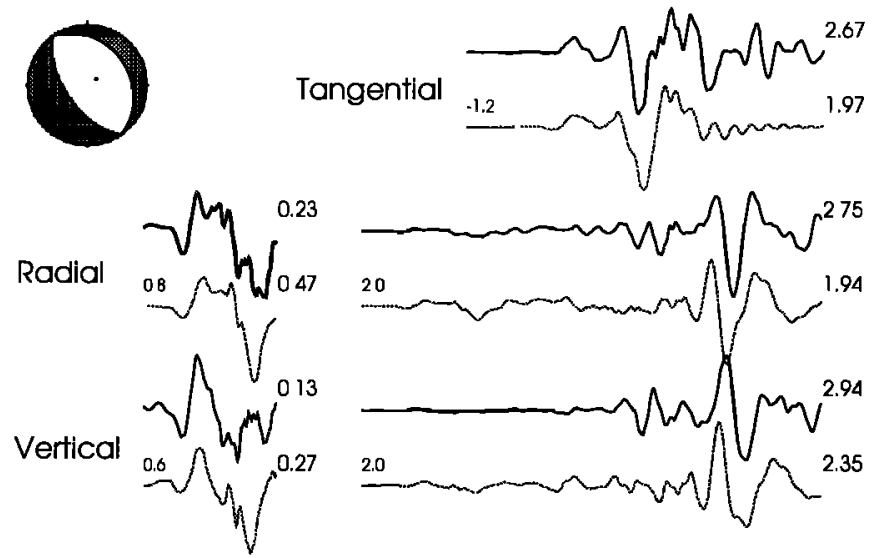

Pnl

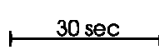

Whole waveform

Figure 10. Results from a single-station source inversion for the Almeria (93357) event in southern Spain recorded at PAB. The Green's functions were calculated using a 1-D velocity model.
In Figure 12 we present a multiple station inversion for the Gafsa event using this hybrid method. Note the very different character of the surface waves at different stations and the fit by the synthetic waveforms. Although there is still a mismatch for some records, especially at larger distances, we are able to fit the waveforms much better than with a 1-D model. The mechanism that we obtained from this inversion is similar to the Harvard CMT solution and our own surface wave solution. The same holds true for the 1988 north Algerian event which was recorded by the NARSILIHA network which was deployed throughout Spain [Nolet et al., 1991] (Figure 13). Again, the very different character of the surface waves can be reproduced using our regionalized model.

Since monitoring efforts are based on a limited number of stations, we applied this method to observations from a single station. In Figure 14 we present the result from a single station inversion using the hybrid method for a master event in North Africa recorded by station PAB. The solution for Mostagenem event (94230) is identical to the solution that we obtained using surface waves recorded at several regional stations as well as to the Harvard CMT solution.

Another example is given in Figure 15 where we studied an event (Tipasa 1,89302 ) for which only data from station TOL was available. Again, we were able to obtain a solution with a good fit for both the $P_{n l}$ and the surface waves. So far, all the hybrid inversions have been carried out with long period ( $15 \mathrm{~s}$ ) filtered data because our regionalization is not quite sufficient yet for shorter periods. The steeply dipping east-west trending plane is similar to 


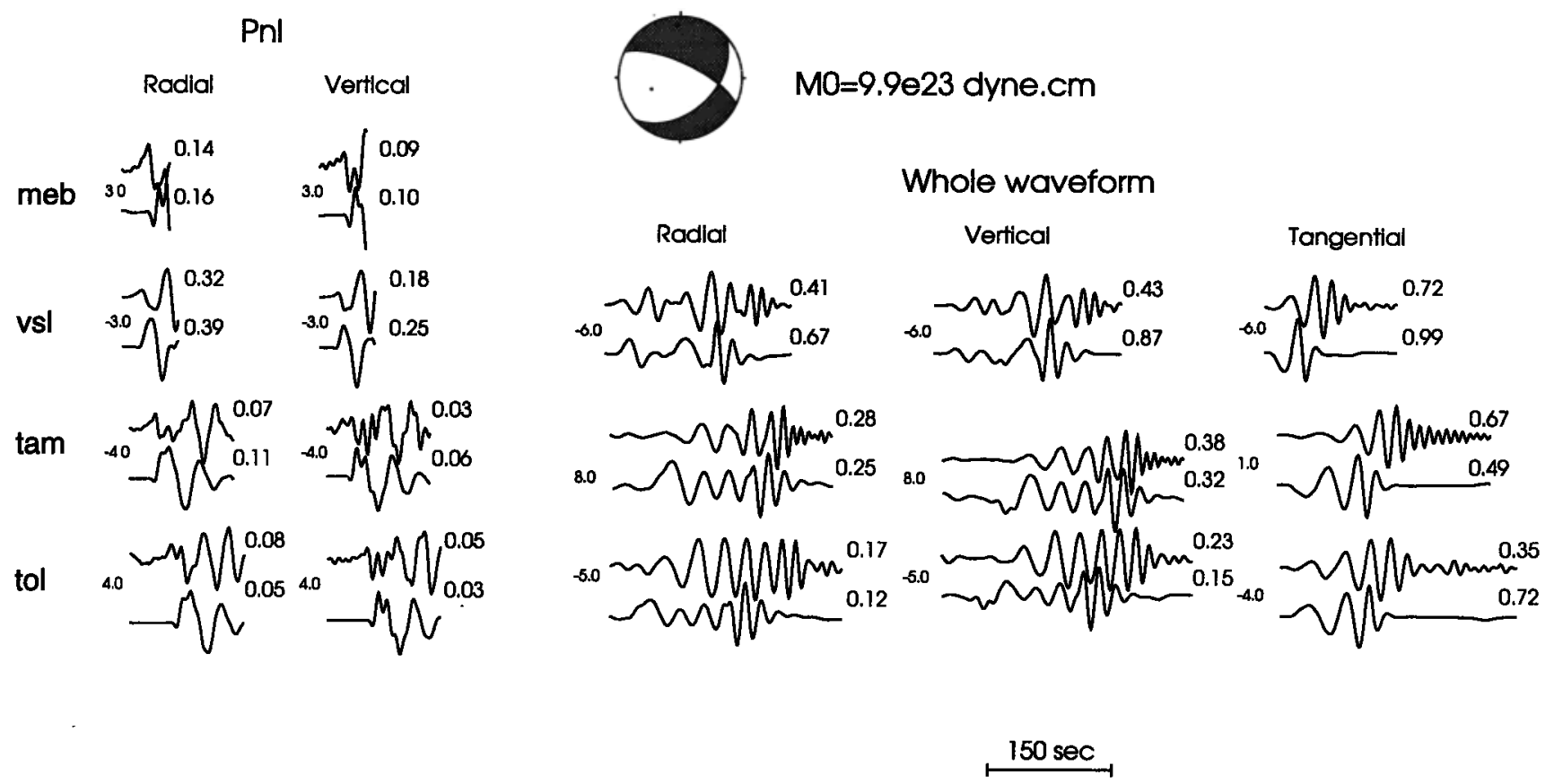

Figure 11. Inversion results using the method of Zhao and Helmberger [1994] for the Gafsa event using a 1-D model. It is inconsistent with the Harvard CMT as well as our own moment tensor solution obtained from surface wave inversion. The model used here was developed using our moment tensor solution and the TOL data. It is clear that such a 1-D model, even at longer periods, cannot fit the surface waves at all stations at the same time. Top traces of every pair are data, bottom traces are synthetic seismograms. The time shift between data and synthetics in seconds is printed at the beginning of every pair.

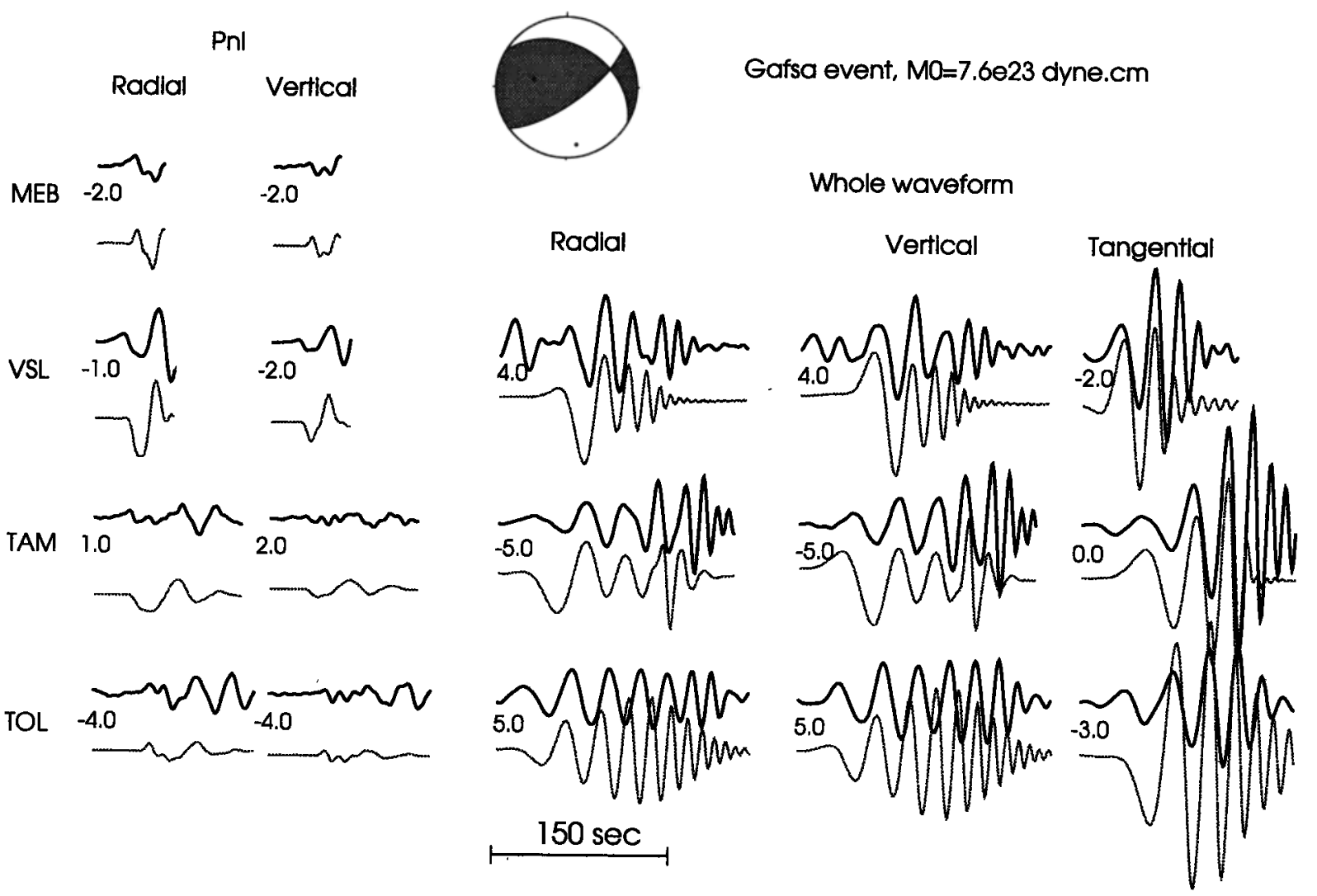

Figure 12. Source estimation for the June 12, 1992 Gafsa event $\left(m_{b}=4.8\right)$ and omparison of long-period data and synthetics. Top traces of every pair are data, bottom traces are synthetics. Time shifts to the left of the traces are in seconds and represent the shift between the synthetic seismograms and the data. The model used for the $P_{n l}$ waves is the same as that used for north Algeria event (88305), except that the crust has a thickness of 37 instead of $28 \mathrm{~km}$. The surface wave portions were calculated using the regionalized model. 
$\mathrm{Pnl}$

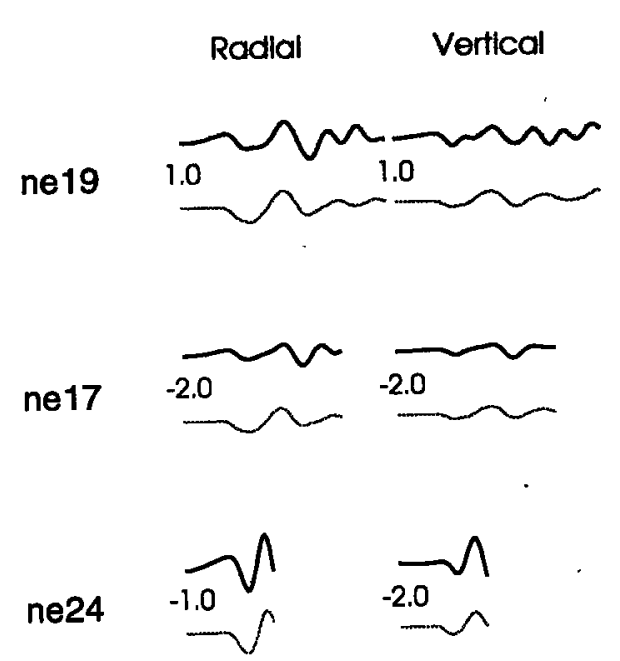

ne14

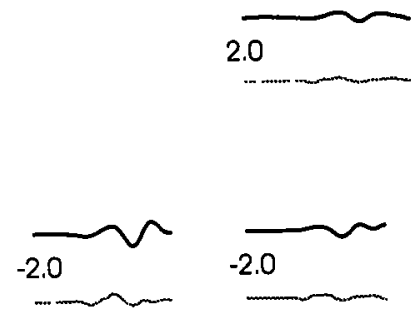

ne22

ne20

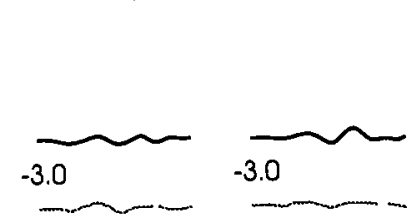

Whole waveform

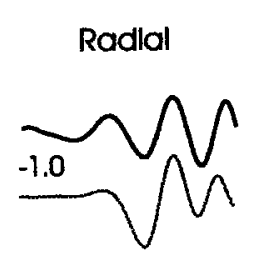

Vertical

Tangential
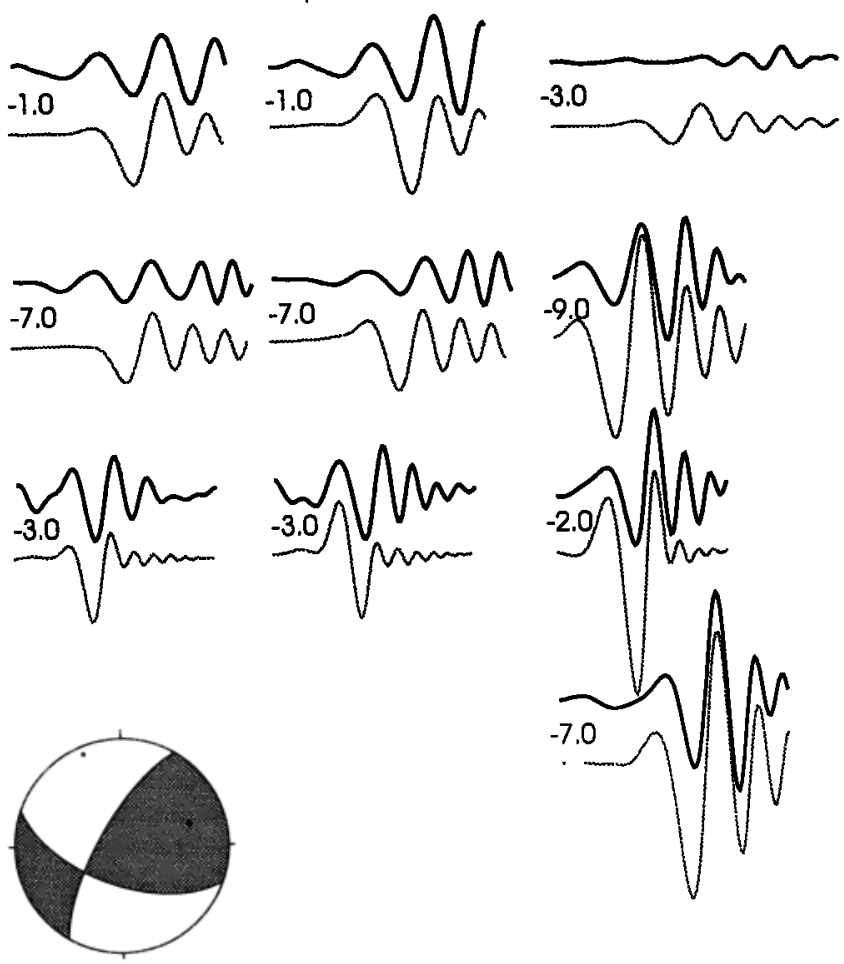

$-3$

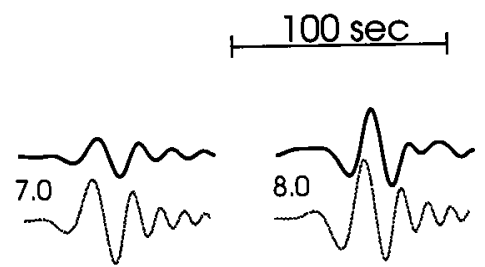

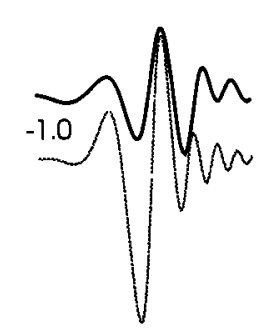

Figure 13. Source estimation for north Algeria event (88305). Comparison of long-period ( $>10 \mathrm{~s}$ for $P_{n l},>20 \mathrm{~s}$ for surface waves) data. Every waveform pair consists of (top) data and (bottom) synthetics. The time shifts between data and synthetics are shown in seconds, with positive numbers indicating fast synthetics. Amplitudes for the $P_{n l}$ waves are scaled by the distance.

that found by Meghraoui [1991] and is well resolved with first motion data. It is also consistent with the aftershock distribution which dips steeply to the northwest. The secondary plane is poorly resolved, and Meghraoui's [1991] thrust solution could easily be more oblique.

\section{Discussion}

In our analysis of seismological observation in the western Mediterranean region we have established seismic characteristics of different tectonic regions. With the exception of Spain, we found that the upper mantle has low velocities which is typical for tectonically active regions. For the North African shield areas, this observation may seem counterintuitive, but it is quite consistent with the Tertiary magmatic activity that occurred here. Lesquer et $a l$. [1990] discussed the correlation between low upper mantle velocities and high heat flow in the area and concluded that the temperature of the upper mantle is elevated and that partial melting might even be taking place. Our observations do indicate that the crustal structure of the shields is very simple with weak lateral heterogeneity and that they are excellent waveguides for $L g$ propagation.

In contrast to that, the seismic structure of the mountain ranges of Morocco, Algeria and southern Spain as well as the Alboran Sea are very complex. $\mathrm{Lg}$ waves do propagate through the mountain ranges but show considerable scatter which is caused by lateral heterogeneity. This heterogeneity has several causes, e.g., the existence of well-developed sedimentary basins along the coast and variation in Moho depth, ranging from $37 \mathrm{~km}$ inland up to $45 \mathrm{~km}$ under the Atlas and Rif Mountains to $20 \mathrm{~km}$ under the Mediterranean (Balearic basin). As expected, the oceanic crust of the Mediterranean is a very poor waveguide for $L g$ waves, which are completely blocked for paths crossing the Mediterranean, which, in the case of nuclear monitoring, necessitates the use of non- $L g$ 


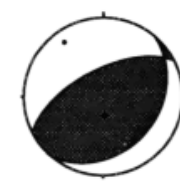

\section{Tangential}

\section{Whole waveform}

Pnl
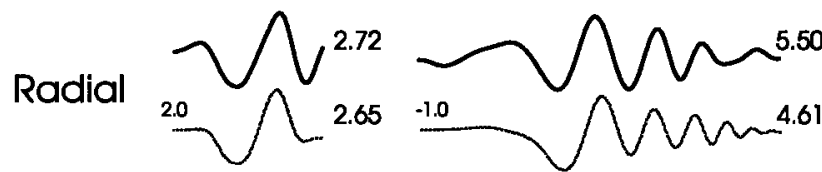

Vertical
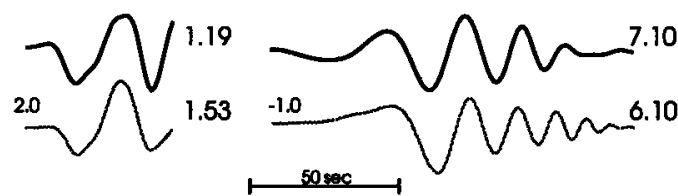

Figure 14. Single station inversion for the Mostaganem earthquake (94230) using the hybrid method. Left traces are $P_{n l}$ waveform pairs, (top) data and (bottom) synthetic. The right-hand traces are the surface-waves, calculated using the mixed path method: tangential (top pair), radial (middle pair) and vertical (bottom pair). The number at the beginning of each pair represent the timeshift in seconds, the right-hand numbers are the amplitudes.

based discrimination techniques [e.g., Woods and Helmberger, 1997], and/or the use of stations that are located on the same continent as is being monitored.

The positive gradient in the seismic velocities that we found below the Moho of North Africa is similar in character to the results found by Pino and Helmberger [1997] for the upper mantle under the western Mediterranean. We have shown that this kind of structure results in relatively sharp $P_{n}$ arrivals, which facilitates the identification of depth phases in the records at regional distances. Given the fact that depth, especially for crustal earthquakes, is very hard to resolve using first arrivals only, we believe that in this particular region it is feasible to use regionally observed depth phases in routine earthquake locations. Such information is invaluable for nuclear monitoring operations because of the overlap between the deep earthquake and explosion populations in most discrimination studies. Tectonic studies would also benefit from improved depth resolutions, e.g., studies linking seismicity distributions to the fate of the subducted slabs or detached lithosphere [e.g., Seber et al., 1996b].

We have shown how regionalization can be very useful in tectonically complex areas like the western Mediterranean. Although we have applied this regionalization to surface waves so far, it can easily be extended to include other observed wave characteristics like $P_{n}$ velocities and attenuation. Our present regionalization should be refined so that we can include shorter periods, which will improve the constraints on the mechanism and depth and which will lower the size treshold of the events that can be analyzed this way.

The combination of this regionalization and Zhao and Helmberger's [1994] cut-and-paste method proves to be very effective for source inversion in laterally varying structures, as we have encountered in the present study region. Given the fact that we can reliably invert for source mechanisms with one or two stations, we conclude that this method is very useful for routine source mechanism determinations throughout the Mediterranean region for events down to magnitude 4 .

We have observed that teleseismic observations of body waves from this region are generally of poor quality, which may be due to complexities in local structure. This emphasizes the importance of using regional data, as well as data from triplication distances $(\Delta<$ $30^{\circ}$ ), for which excellent data are available, especially from European stations. More calibration studies are needed before we are able to use these data effectively.

Our current results are generally consistent with tectonic models of the region [e.g., Buforn et al., 1995; Westaway, 1990]. The character of deformation of the North African margin changes from a narrow band of primarily thrust events in the east (Tunisia, Algeria)

Whole waveform
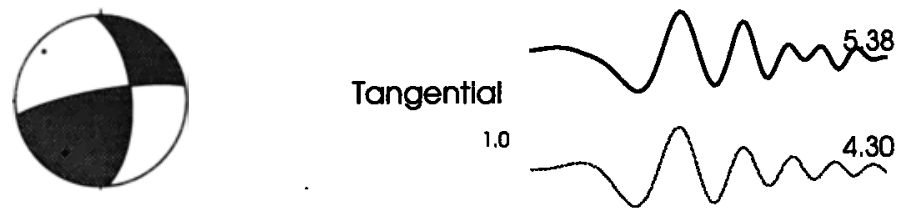

Pni
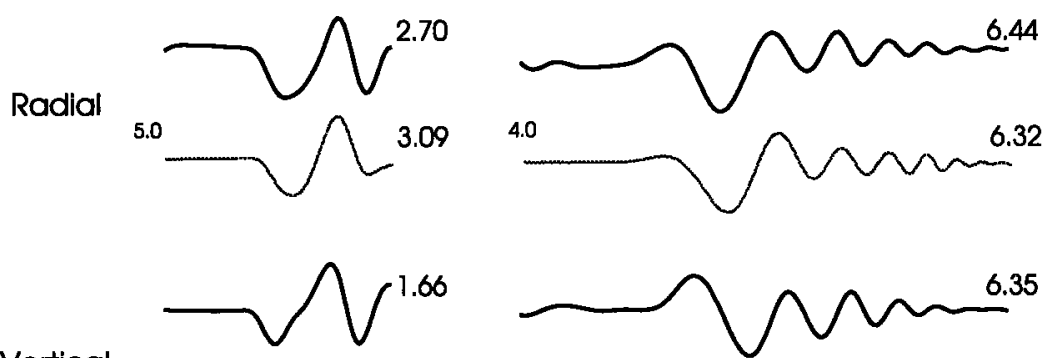

Vertical
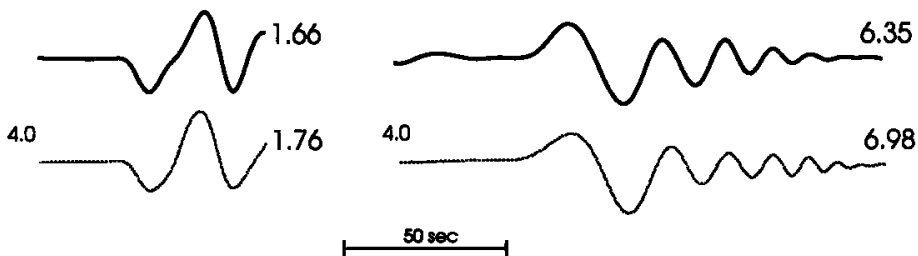

Figure 15. Single-station inversion for the Tipasa 1 earthquake (89302) using the hybrid method. Labels and arrangement are similar to those in Figure 14. 
to a wide zone of both dip-slip events as well as strike-slip events in Morocco. This may reflect the change in orientation of the relative plate motions from N-S in the east to NW-SE in the west, i.e., oblique to the plate boundary, which is a consequence of the location of the Europe-Africa rotation pole, west of Gibraltar [e.g., Westaway, 1990; Meghraoui et al., 1996].

\section{References}

Ambraseys, N.N., J. Vogt, and R.D. Adams, The Algerian earthquake of 24 June 1910: A case history, Tectonophysics, 193, 205-213, 1991 a.

Ambraseys, N.N., J. Vogt, and R.D. Adams, Seismicity of the central Cheliff Valley in Algeria, in Seismicity, Seismotectonics and Seismic Risk of the Ibero-Maghrebian Region, edited by J. Mezcua and A. Udías, pp. 41-50, Inst. Geogr. Nac., Madrid, Spain, $1991 \mathrm{~b}$.

Aoudia, A., and M. Meghraoui, Seismotectonics in the Tell Atlas of Algeria: The Cavaignac (Abou El Hassan) earthquake of 25.08.1922 $\left(M_{S}=\right.$ 5.9), Tectonophysics, 248, 263-276, 1995.

Banda, E., Crustal parameters in the Iberian Peninsula, Phys. Earth Planet. Inter., 51, 222-225, 1988.

Barazangi, M., E. Fielding, B. Isacks and D. Seber (1996). Geophysical and Geological databases and CTBT monitoring: a case study of the Middle East, in Monitoring a Comprehensive Test Ban Treaty, edited by Husebye, E.S., and A.M.Dainty, Pp. 197-224, Kluwer Academic Pub., Norwell Mass., 1996.

Buforn, E., A. Udías, and R. Madariaga, Intermediate and deep earthquakes in Spain, Pure Appl. Geophys., 136, 375-393, 1991.

Bufom, E., C. Sanz de Galdeano, and A. Udías, Seismotectonics of the Ibero-Maghrebian region. Tecionophysics, 248, 247-261, 1995.

Cahen, L., and N.J. Snelling, The Geochronology and Evolution of Africa, 512 pp., Clarendon, Oxford, 1984.

Cherkaoui, T.-E., F. Medina, and D. Hatzfeld, The Agadir earthquake of February, 29, 1960. Examination of some of the parameters, in Seismicity, Seismotectonics and Seismic Risk of the Ibero-Maghrebian Region, edited by J. Mezcua and A. Udias, pp. 133-148, Inst. Geogr. Nac., Madrid, Spain, 1991.

Corchete, V., J. Badal, F.J. Seron, and A. Soria, Tomographic images of the Iberian subcrustal lithosphere and astenosphere, J. Geophys. Res., I00, 24,133-24,146, 1995.

Deschamps, A., Y. Gaudemer, and A. Cisternas, The El Asnam, Algeria, earthquake of 10 October 1980: Multiple source mechanism determined from long-period records, Bull. Seismol. Soc. Am., 72, 1111-1128, 1982.

Deschamps, A., M. Bezzeghoud and A. Bounif , Seismological study of the Constantine (Algeria) earthquake (27 October 1985), in Seismicity, Seismotectonics and Seismic Risk of the Ibero-Maghrebian Region, edited by J. Mezcua and A. Udias, pp. 163-173, Inst. Geogr. Nac., Madrid, Spain, 1991.

Doglioni, C., E. Gueguen, F. Sàbat, and M. Fernandez, The western Mediterranean extensional basins and the Alpine orogen, Terra Nova, 9 , 109-112, 1997.

Dziewonski, A.M., and J. Steim, Dispersion and attenuation of mantle waves through waveform inversion, Geophys. J. R. Astron. Soc., 70, 503-527, 1982.

Dziewonski, A.M., and J.H. Woodhouse, Studies of the seismic source using normal-mode theory, in Earthquakes: Observation. Theory and Interpretation, edited by Kanamori, H. and E. Boschi, pp. 45-137, North-Holland, New York, 1983.

Giardini, D., E. Boschi, and B. Palumbo, Moment tensor inversion from MedNet data (2) Regional earthquakes of the Mediterranean, Geophys. Res. Lett., 20, 273-276, 1993.

Hadiouche, O., and N. Jobert., Geographical distribution of surface-wave velocities and 3-D upper mantle structure in Africa, Geophys. J. Int., 95 , 87-109, 1988.

Helmberger, D.V., Theory and application of synthetic seismograms, in Earthquakes: Observation, Theory and Interpretation, edited by Kanamori, H. and E. Boschi, pp. 174-222, North-Holland, New York, 1983.

Johnston, A.C., Seismic moment assessment of earthquakes in stable continental regions, 3, New Madrid 1811-1812, Charleston 1886 and Lisbon 1755, Geophys. J. Int., 126, 314-344, 1996.

Kikuchi, M., and $\mathrm{H}$. Kanamori, Inversion of complex body-waves, III, Bull. Seismol. Soc. Am., 8I, 2335-2350, 1991.
Landismann, M., A. Dziewonski, and Y Satô, Recent improvements in the analysis of surface wave observations, Geophys. J. R. Astron. Soc., 17, 369-403, 1969.

Lesquer, A., D. Takherist, J.M. Dautria, and O. Hadiouche, Geophysical and petrological evidence for the presence of an "anomalous" upper mantle beneath the Sahara basins (Algeria), Earth Planet. Sci. Lett., 96, 407.418, 1990.

Medina, F., Present-day state of stress in northern Morocco from focal mechanism analysis, J. Struct. Geol., 17, 1035-1046, 1995.

Meghraoui, M., Blind reverse faulting system associated with the Mont Chenoua-Tipaza earthquake of 29 October 1989 (north-central Algeria), Terra Nova, 3, 84-92, 1991.

Meghraoui, M., J.-L. Morel, J. Andrieux, and M. Dahmani, Tectonique plio-quaternaire de la chaîne tello-riffaine et de la mer d'Alboran. Une zone complexe de convergence continent-continent, Bull. Soc. Géol. Fr., 141-157, 1996.

Mezcua, J., and J. Rueda, Seismological evidence for a delamination process in the lithosphere under the Alboran Sea, Geophys. J. Int., I29, F1-F8, 1997.

Nakanishi, I., and H. Kanamori, Effects of lateral heterogeneity and source process time on the linear moment tensor inversion of long-period Rayleigh waves, Bull. Seismol. Soc. Am., 72, 2063-2080, 1982.

Nolet, G., B. Dost, and H. Paulssen, The NARS array. In MedNet: The Broad-band Seismic Network for the Mediterranean, pp. 76-82, Il Cigno Galileo Galilei, Rome, 1991.

Pino, N.A., and D.V. Helmberger, Upper mantle compressional velocity structure beneath the West Mediterranean basin, J. Geophys. Res., 102, 2953-2967, 1997.

Research Group for Lithospheric Structure in Tunisia, The EGT'85 seismic experiment in Tunisia: A reconnaissance of the deep structures, Tectonophysics 207, 245-267, 1992.

Rueda, J., J. Mezcua, and M. Sánchez Ramos, La serie sísmica de Adra (Almería) de 1993-1994 y sus principales consequencias seismotectónicas, Avan. Geofis. Geod., 1, 91-98, 1996.

Seber, D., M. Barazangi, B.A. Tadili, M. Ramdani, A. Ibenbrahim, and D. Ben Sari, Three-dimensional upper mantle structure beneath the intraplate Atlas and interplate Rif Mountains of Morocco, J. Geophys. Res., 101, 3125-3138, 1996a.

Seber, D., M. Barazangi, A. Ibenbrahim, and A. Demnati, Geophysical evidence for lithospheric delamination berneath the Alboran Sea and Betic-Rif Mountains, Nature, 379, 785-790, 1996b.

Snieder, R., Large-scale waveform inversion of surface waves for lateral heterogeneity 2. Application to surface waves in Europe and the Mediterranean, J. Geophys.Res., 93, 12,067-12,080, 1988.

Thio, H.K., and H. Kanamori, Moment-tensor inversions for local earthquakes using surface waves recorded at TERRAscope, Bull. Seismol. Soc. Am., 85, 1021-1038, 1995.

Westaway, R., Present-day kinematics of the plate boundary zone between Africa and Europe, from the Azores to the Aegean. Earth Planet. Sci. Lett., 96, 393-406, 1990.

Woods, B., and D.V. Helmberger, Regional seismic discriminants using wave train energy ratios, Bull. Seismol. Soc. Am., 87, 589-601, 1997.

Working Group for Deep Seismic Sounding in Spain 1974-1975, Deep seismic soundings in southem Spain, Pure Appl. Geophys., 115, 721$735,1977$.

Zhao, L.S. and D.V. Helmberger, Source estimation from broadband regional seismograms, Bull. Seismol. Soc. Am., 84, 91-104, 1994.

Zhu, L., D.V. Helmberger, C.K. Saikia and B.B. Woods, Regional waveform calibration in the Pamir-Hindu Kush region, J. Geophys. Res., 102, 22,799-22,813, 1997.

Zielhuis, A., S-wave velocity below Europe from delay-time and waveform inversions, PhD thesis, 200 pp., Rijksuniversiteit Utrecht, 1992.

D.V. Helmberger and X. Song, Seismological Laboratory 252-21, California Institute of Technology, Pasadena, Ca 91125 . (e-mail: helm@gps.caltech.edu; xis@gps.caltech.edu)

C.K. Saikia, H.K. Thio, and B.B. Woods, Woodward-Clyde Federal Services, 566 El Dorado Street, Pasadena, Ca 91101 . (e-mail: cksaiki0@wcc.com; hkthiox0@wcc.com; bbwoods0@wcc.com)

(Received June 12, 1997; revised February 12, 1998; accepted April 28, 1998.) 